\title{
Tsunami Wave Analysis and Possibility of Splay Fault Rupture During the 2004 Indian Ocean Earthquake
}

\author{
Nora DeDontney ${ }^{1}$ and James R. Rice ${ }^{1,2}$
}

\begin{abstract}
The 2004 Indian Ocean tsunami was observed by two satellites, close in space and time, that traversed the Indian Ocean $2 \mathrm{~h}$ after the Sumatra-Andaman earthquake, but which observed different tsunami lead wave morphologies. The earlier satellite, Jason-1, recorded a lead wave with two peaks of similar amplitude and wavelength, while the later satellite, TOPEX/ Poseidon, recorded a lead wave with only one longer wavelength uplift. To resolve this disparity, we examine the travel paths of long wavelength waves over the seafloor bathymetry. Waves traveling from the margin will traverse significantly different paths to arrive at the two satellite transects. The result is that the satellites are sensitive to different parts of the margin; Jason-1 is highly sensitive to the margin in the area of the epicenter, while TOPEX is sensitive to a more northerly section. By developing solutions of the ocean gravity wave equations, accounting for dispersion, we show that the double peak of the Jason-1 satellite observations are consistent with coseismic rupture of a splay fault of limited along-strike extent, located north of Simeulue Island. The doubly peaked morphology can be reproduced with co-activation of the subduction zone interface and the splay fault, which creates a seafloor uplift pattern with two distinct areas of uplift. The Jason-1 satellite is sensitive to a splay fault in this portion of the margin, whereas the TOPEX satellite would not be significantly affected by this uplift pattern. By back-projecting satellite observation points to the margin, we constrain the location of the proposed splay fault and find that it correlates with a bathymetric high. The aftershock locations, uplift of corals on Simeulue Island and a fault scarp on Pulau Salaut Besar are also consistent with the activation of a splay fault in the area delimited by the back-projection. Our work also shows that it is critical to fully capture gravity wave dispersion in order to represent features of the lead wave profile that may not be as well characterized by the shallow water (long-wavelength) model. It is also necessary to account for dispersion so as to precisely assess wavefront travel times; this leads us to conclude that the rupture must have reached very near to the trench and propagated with an updip rupture velocity of order $2.0 \mathrm{~km} / \mathrm{s}$ or more.
\end{abstract}

Key words: Tsunami, dispersion, splay fault, Sumatra.

1 Department of Earth and Planetary Sciences, Harvard University, 20 Oxford St., Cambridge, MA 02138, USA. E-mail: ndedontn@post.harvard.edu

2 School of Engineering and Applied Science, Harvard University, 29 Oxford St., Cambridge, MA 02138, USA.

\section{Introduction}

Slip on a splay fault can greatly affect the resulting tsunami. Splay faults dip more steeply than the subduction interface, so only a small amount of slip is needed to produce a large vertical uplift and resulting tsunami. Also, since the splay fault reaches the seafloor closer to the coast than the subduction interface, the local tsunami arrival time can be significantly earlier if a splay fault is activated. The importance of this issue was highlighted by the recent simulations of WENDT et al. (2009) who coupled dynamic rupture models to tsunami generation, illustrating the large influence of splay fault rupture on the resulting tsunami.

Constraints on the activation of splay faults are needed to determine if they pose a significant hazard during major subduction zone events. Therefore, we examine the 2004 Indian Ocean tsunami for evidence of splay fault activation during the Sumatra-Andaman earthquake.

\subsection{Observations of the 2004 Earthquake and Tsunami}

The Indian Ocean tsunami was directly observed by multiple satellites measuring sea surface altimetry at various times during the wave propagation (SмIтH et al., 2005; Gower, 2007). Two satellites, Jason-1 and TOPEX/Poseidon (hereafter TOPEX), made transects of the Indian Ocean approximately $2 \mathrm{~h}$ after the start of the earthquake; each recorded a lead wave with differing characteristics (Fig. 1). The Jason-1 altimetry measurements clearly show a doublypeaked lead wave. The older satellite, TOPEX, did not record a fully continuous signal, but it did record a lead wave of only one peak of longer wavelength. 


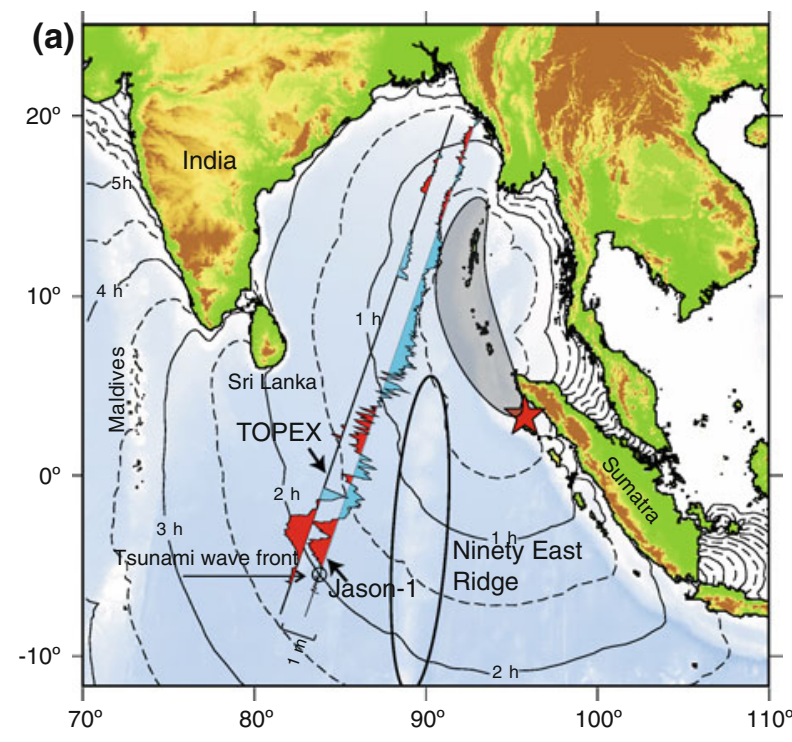

(b)

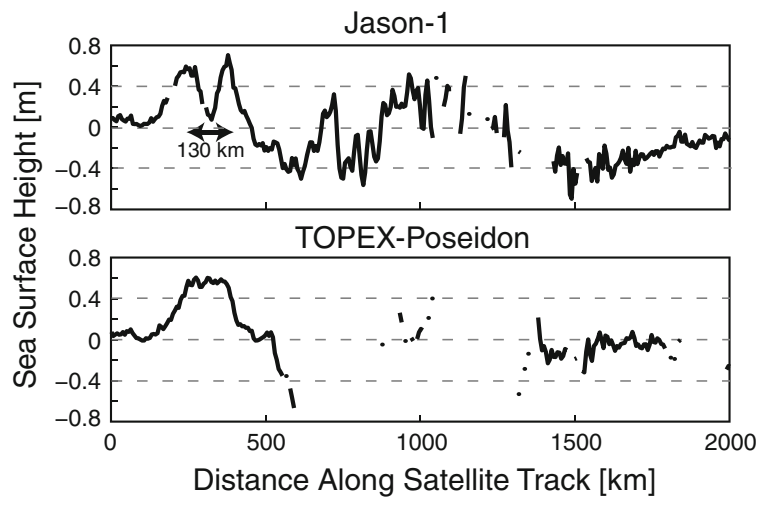

Figure 1

The Jason-1 and TOPEX/Poseidon satellite measurements of sea surface altimetry over the Indian Ocean $2 \mathrm{~h}$ after the earthquake. a The satellite transects were different and the wave propagated over the Ninety East Ridge [modified from Kulikov (2005), with isochrones attributed to K. Satake]. Red star shows the earthquake epicenter and gray shaded region is the approximate area that ruptured during the event. b Sea surface height measurements by the two satellites (origin chosen at an arbitrary location). The lead wave of the Jason-1 measurement is doubly peaked and the distance between the peaks is $130 \mathrm{~km}(\sim 112 \mathrm{~km}$ perpendicular to the wavefront). Note that the data have not been processed other than the standard processing techniques applied before data reporting to the Physical Oceanography Data Active Archive Center (PODAAC)

The 2004 Sumatra-Andaman earthquake ruptured a 1,200-1,300 km stretch of the subduction zone as it traveled north at a velocity of $2.0-2.8 \mathrm{~km} / \mathrm{s}$, over roughly 500-600 s (AMmON et al., 2005; LAY et al., 2005; Ishil et al., 2005; GuILBert et al., 2005; TsAI et al., 2005). Despite the large rupture area, we show that only the slip distribution in the area of rupture initiation, off the coast of northern Sumatra, determines the characteristics of the lead wave that travels towards the southwest across the Indian Ocean, where the satellite tracks traversed the wave front. In this source area, multiple ship-based investigations of the seafloor took place during the months following the event (Seeber et al., 2007; Нenstock et al., 2006; FISHER et al., 2007; SIBUET et al., 2007), but these mostly focused on the deformation near the trench and further to the north than the location of the splay fault we consider. ROV dives as well as bathymetric and seismic reflection data found evidence for recent deformation both near the trench (FISHER et al., 2007; Henstock et al., 2006; Mosher et al., 2008) and about $120 \mathrm{~km}$ from the deformation front (SEEBER et al., 2007).
The area of ship-based investigations is also the location of Ocean Bottom Seismometer (OBS) deployments following the event (ARAKI et al., 2006; SiBuet et al., 2007). These OBS deployments found that aftershocks clustered into bands of seismicity above the subduction interface, at roughly 50 and $100 \mathrm{~km}$ from the trench, that correlate with bathymetric features. This indicates the presence of major splay faults off the coast of northern Sumatra that possibly ruptured during the earthquake (ARAKI et al., 2006; Sibuet et al., 2007; Lin et al., 2009). These splay faults may be similar to a structure observed in the Nankai subduction zone that branches from the subduction interface (PARK et al., 2002). The OBS deployments only cover a small area of the margin, so additional aftershock studies are required to better characterize the full source region (ENGDAHL et al., 2007; Dewey et al., 2007; PesiceK et al., 2010; Tilmann et al., 2010).

PlafKer et al. (2006) suggest that eyewitness accounts of the local Sumatra tsunami arriving earlier-than-expected, like those noted by the field team Tsunarisque (LAvigne et al., 2009), could be 
due to a secondary source on the western side of the Aceh basin. LOEVENBRUCK et al. (2007) showed that slip on a splay fault would result in tsunami arrival times in northern Sumatra that are consistent with those observations. A secondary source, with a surface expression located closer to shore, was also used to explain earlier than expected tsunami arrival times due to the 1983 Nihonkai-Chubu earthquake (Shuto et al., 1995). BANERJEe et al. (2007) addressed the possibility of splay fault activation off the coast of northern Sumatra using GPS data, but were unable to reach a conclusion about whether or not a splay fault was consistent with observations.

Support for the plausibility of coseismic splay fault activation comes from the dynamic rupture propagation models of KAME et al. (2003), who show that splay fault rupture is likely in the Nankai subduction zone and that simultaneous rupture on two fault segments is a common occurrence.

\subsection{Objectives of Current Work}

Accurate hazard assessment and warnings depend on an understanding of the rupture process and knowledge of the likelihood of coseismic rupture of splay faults. Seismic and geodetic inversions generally assume the fault plane a priori, and have not been able to determine if splay fault ruptures occur (BANERJEe et al., 2007). Local tsunami waveform inversions of earthquakes in the Nankai subduction zone have also been unable to determine if splay faults have ruptured (e.g., ВАВА et al., 2006; КАТО, 1983; TANiOKa and Satake, 2001). We build on the work of DeDontney and Rice (2007) and seek to determine if there is any evidence of splay rupture during the 2004 Sumatra-Andaman earthquake. To accomplish this we use a variety of methods, including back-projection, dispersive wave propagation, and an examination of geodetic and seismic data. While we cannot rule out other explanations for the observations, multiple lines of evidence suggest that coseismic splay fault activation likely occurred.

The first issue that we address is the disparity between the two satellite observations. Long wavelength waves respond to bathymetric features, such as the Ninety East Ridge (Fig. 1a), by a curvature of the ray path of propagation. We investigate the role of path curvature by back-projecting ray paths from points of the observed waveforms. This determines the origin of the satellite signal and constrains potential uplift patterns in the source area off the coast of northern Sumatra. Using this method, we are able to determine if there is a path effect, and if the two satellites are sensitive to different portions of the margin. We also examine the terminal locations of the ray paths and determine if additional insight into the rupture process can be gained.

We also use forward models of wave propagation that allow for slip on both the subduction zone interface and a splay fault. We examine the waveform of the ocean-bound tsunami to determine if there is an identifiable signature due to splay faulting. We compare the modeled waveform to the observations of the double peak, by the Jason-1 satellite, to determine if splay fault activation can explain the distinct wave morphology.

Using forward models, we investigate the importance of dispersion in allowing the waveform to evolve with distance traveled. Some models do not include dispersion, but both the Jason-1 track data (KuLIKov and Medvedev, 2005) and hydrophone records (HaNSON and Bowman, 2005; OKal et al., 2007), as well as basic gravity wave theory (e.g., MeI, 1989), indicate that the waves are dispersive. Propagating the wave using shallow water theory, which translates all wave numbers at the same shallow water wave speed (SWWS), does not allow the tsunami waveform to evolve with time. This theory also neglects the dispersion process, which we show by exact hydrodynamic calculations (but which are possible only for a simplified ocean model of uniform depth) to be important for replicating a doubly-peaked wave.

We also examine the uplift of corals on Simeulue island (MeltzNer et al., 2006) to assess if a large local gradient in uplift can be explained by a model that includes splay fault rupture. We discuss the observations of a fault scarp on a small island to the northwest of Simeulue Island, Pulau Salaut Besar (Meltzner et al., 2010), and how this could be the result of splay fault activation. In addition, we study the aftershock distribution and evaluate if it is consistent with the Coulomb stress changes that would be caused by rupture of both a splay fault and the subduction interface. 


\section{Satellite Data}

Cycle 109, pass 129, of the Jason-1 orbit and cycle 452, pass 129, of the TOPEX orbit captured the tsunami $2 \mathrm{~h}$ after the earthquake, while the lead wave was near $5^{\circ} \mathrm{S}$ (Fig. 1a). While close to each other, these two satellites did not traverse the same path. TOPEX crossed the equator at $84.33^{\circ} \mathrm{E}$, while Jason1 crossed the equator $160 \mathrm{~km}$ to the east, at $85.75^{\circ} \mathrm{E}$. Despite the close proximity of the satellite transects, there are significant differences between the two satellite observations of the lead wave. The Jason-1 data clearly show a doubly-peaked lead wave without a dip below mean sea surface height ( $\mathrm{SSH}$ ) in the trough (Fig. 1b). Data from TOPEX instead show a single uplift of longer wavelength. The distance between the tops of the Jason-1 peaks is $112 \pm 6 \mathrm{~km}$ perpendicular to the wavefront. This was found by using a $30 \pm 5^{\circ}$ obliquity of the satellite transect crossing the wavefront, determined from the isochrones of the tsunami wavefront computed by $\mathrm{K}$. Satake (as reported by KuLIKov (2005) and shown in Fig. 1a), which agree with the isochrones of Tiтоv et al. (2005). Additionally, TOPEX lagged behind Jason- 1 by $7 \mathrm{~min}$ and $33 \mathrm{~s}$ at the equator crossing, in which time the wavefront of K. Satake would have advanced $\sim 98 \mathrm{~km}$. The small differences in time and space of the sea surface measurements led to different signatures being recorded by the two satellites; in the ensuing sections we discuss the cause of these differences. Two additional satellites traversed the Indian ocean at later times, but due to timing and modeling limitations, we do not discuss these observations here.

\section{Back-Projection of Tsunami Waveform}

We back-project the tsunami lead wave to determine the tsunami's origin and examine the effect of the bathymetry on the propagating wave. Differences between the back-projections of the two satellite observations can help us understand the reason for the observed disparity between the lead wave morphologies.

The morphology of the tsunami lead wave is the result of the seafloor uplift pattern in the area of rupture initiation and the bathymetry over which the wave travels. Bathymetry affects both the wave travel time and the path of the wave. The travel time is affected because of the depth dependence of the shallow water wave speed (SWWS), $c(x, y)=$ $\sqrt{g H(x, y)}$, where $c$ is the velocity, $g$ is gravity, $H$ is ocean depth and $x$ and $y$ are horizontal coordinates (e.g., MeI, 1989). Waves travel more slowly over shallower water, so the bathymetry affects the arrival time. This is especially important to consider since tsunami waves originate from uplifted seafloor in the shallow accretionary prism, where waves travel more slowly than in the deep open ocean.

The path of a wave is altered by gradients in bathymetry, resulting in waves that do not necessarily follow a straight path in the open ocean. We are able to assess how the seafloor bathymetry will refract the propagating waves using this back-projection method. Bathymetric features, like the Ninety East Ridge (Fig. 1a), alter the velocity of wave propagation, and the gradients in bathymetry refract long wavelength waves. By back-projecting for a specified amount of time, we are able to determine from which parts of the margin the wave could have originated. It is important to understand these bathymetric effects to be able to ascertain the source region for the lead wave and the cause of the discrepancy between the satellite signals.

\subsection{Methodology}

We use the seafloor bathymetry of SMITH and SANDwell (1997) to see how waves are refracted and advanced/retarded due to non-uniform ocean depths. Because we are interested in a propagation distance much smaller than the Earth's radius, and the wave is traveling very close to the equator, it suffices to use a Cartesian approximation and map the bathymetry, reported at latitude and longitude coordinates, directly to a Cartesian grid. We use the SWWS, making the approximation (which we discuss and correct later) that essentially no disturbances can travel faster than the shallow-water wave speed.

By selecting features of the satellite profile such as the initial sea surface uplift, and tracing optimal (shortest travel time) ray paths from this location for a specified time, we are able to determine which parts 
of the margin are capable of affecting the area in which the lead wave is observed. Areas located out of reach of the ray paths are not able to influence the waveform. We specify the travel time to be the difference between the start of the earthquake, at 00:58:53 UTC (NEIC, 2004), and the time that the satellite measured each respective data point that is back-projected. Our modeling does not consider the effects of wave scattering, including reflection, due to variable bathymetry, with the concepts discussed here.

Given the bathymetry variations of the seafloor, the path, $s$, of shortest travel time between two points is not generally a straight line. An increment of wave travel time is $\mathrm{d} t=\mathrm{d} s / c(x, y)=\sqrt{\mathrm{d} x^{2}+\mathrm{d} y^{2}} / c(x, y)$. Considering the dispersive phase speed, $c(k)=$ $\sqrt{g \tanh (k H) / k}$, where $k$ is wavenumber, we know that $\sqrt{g H}$ is the upper bound, approached as $k H \rightarrow 0$, to both phase and group velocities of a time-harmonic surface disturbance in an ocean of constant depth $H$. We here assume that $\sqrt{g H}$ has a similar (approximate) upper bound interpretation for variable $H$. Accepting that, of all the waves that go from point $\left(x_{1}, y_{1}\right)$ to $\left(x_{2}, y_{2}\right)$, the path $y=y(x)$ of shortest cumulative shallow-water travel time will satisfy the Fermat condition,

$$
\int_{x_{1}}^{x_{2}} \frac{\sqrt{1+\left(y^{\prime}\right)^{2}}}{c(x, y)} \mathrm{d} x=\text { minimum }
$$

where $y^{\prime}=\mathrm{d} y / \mathrm{d} x$ and we use the SWWS with $c(x, y)=\sqrt{g H(x, y)}$. The calculus of variations leads to the standard Euler-Lagrange ordinary differential equation (ODE), here in the form

$$
\frac{\mathrm{d}}{\mathrm{d} x}\left(\frac{y^{\prime}}{\sqrt{1+y^{\prime 2}}}\right)-\frac{y^{\prime}}{c \sqrt{1+y^{\prime 2}}} \frac{\partial c}{\partial x}+\frac{1}{c \sqrt{1+y^{\prime 2}}} \frac{\partial c}{\partial y}=0
$$

and using trigonometric identities and the relation that $y^{\prime}=\tan \theta$, this reduces to

$$
\begin{array}{r}
\frac{\mathrm{d} \theta}{\mathrm{d} t}=\sin \theta \frac{\partial c(x, y)}{\partial x}-\cos \theta \frac{\partial c(x, y)}{\partial y} \\
\frac{\mathrm{d} x}{\mathrm{~d} t}=c(x, y) \cos \theta \quad \text { and } \quad \frac{\mathrm{d} y}{\mathrm{~d} t}=c(x, y) \sin \theta
\end{array}
$$

where $x, y$, and $\theta$ are now to be expressed parametrically in terms of shallow water travel time $t$ along the path, and $\mathrm{d} t=\mathrm{d} t(\mathrm{~d} x, \mathrm{~d} y)$ is defined above. Not unexpectedly, given the start with a Fermat-like principle, these are the equations of ray theory based on the SWWS.

To implement this, we choose a satellite observation location, and trace the optimal ray paths from this location for rays with a range in initial take-off angles, $\theta_{0}$, roughly oriented towards Sumatra. The wide range in angles implemented $\left(\theta_{0}\right.$ spans $\left.58^{\circ}\right)$ results in many ray paths that do not approach the margin of Sumatra. We do not consider these ray paths informative, since we are only interested in the travel between the source region and the observation locations.

This type of ray tracing procedure is justified when the wavelength, $\lambda$, of the sea surface wave is much greater than the ocean depth, yet much shorter than the scale of bathymetric features over which it is propagating, $\lambda_{\text {bath}}$. The first relationship is necessary for the long wavelength approximation to be valid, and the second ensures that the bathymetry is slowly varying. The sea surface wavelength of interest, $\lambda \sim$ $100 \mathrm{~km}$, is determined by the length scale in the source region and the recorded altimetry signals. For this wavelength, the requirement that $\lambda \gg H$ is met for realistic ocean depths of $H=1-5 \mathrm{~km}$. To ensure that $\lambda \ll \lambda_{\text {bath }}$, and that this procedure is justified, we must filter the seafloor bathymetry to remove shorter wavelength variations. By only preserving the longer wavelength features, we ensure that the high frequency components of the partial derivatives of the bathymetry do not dominate the ray trace trajectory.

We smooth the seafloor bathymetry using a filter of the form $1 / \cosh \left(k H_{\mathrm{f}}\right)$, where $k$ is the wavenumber and a range of filter depths, $H_{\mathrm{f}}$, are examined. Our final results are for $H_{\mathrm{f}}=36 \mathrm{~km}$. For this $H_{\mathrm{f}}$ value, the amplitudes of wavelengths $>325 \mathrm{~km}$ are $\geq 80 \%$ of their unfiltered value. The amplitudes of shorter wavelengths fall off quickly, thus ensuring that $\lambda<\lambda_{\text {bath }}$.

\subsection{Results: Explaining the Disparity Between Jason-1 and TOPEX Observations}

The pronounced difference between satellite signals could be the result of: (1) the older TOPEX satellite not properly recording the signal (it stopped 
(a) Jason-1

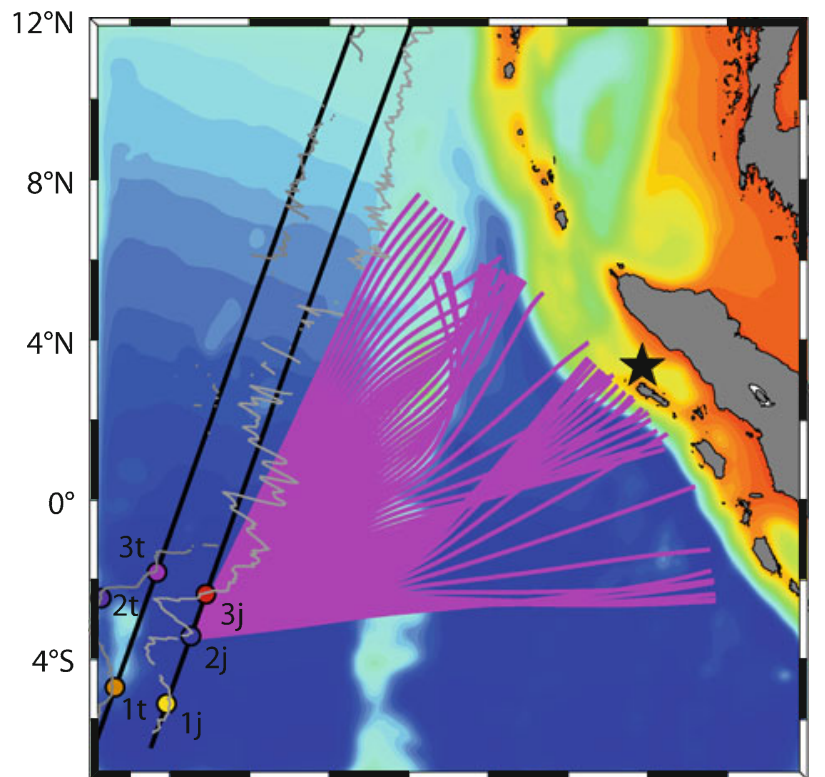

$84^{\circ} \mathrm{E}$

$88^{\circ} \mathrm{E}$ $92^{\circ} \mathrm{E}$

Ocean

Depth (b) TOPEX/Poseidon

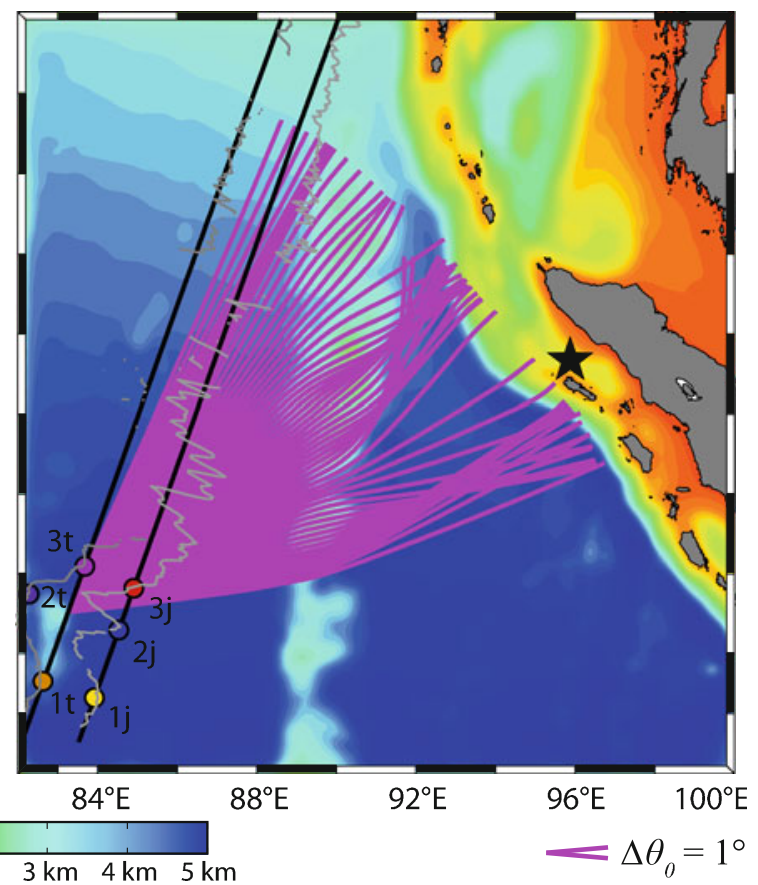

Figure 2

Back-projection of tsunami waveform and satellite track data for a seafloor smoothing filter depth of $36 \mathrm{~km}$. The length of the the ray path is determined by the time between when the satellite measurement was made and the start of the earthquake. a Paths shown for point $2 \mathrm{j}$ of Jason1 satellite track. b Paths shown for an analogous point in the TOPEX track

recording altogether shortly after traversing the lead wave), (2) along-strike variations in slip and the satellites sampling different seafloor uplift patterns, or (3) a complex interference pattern due to wave scattering from bathymetric fluctuations of all wavelengths (not just the longest, which we consider here). It is not possible to prove or disprove option 1, so we do not address it here. Option 3 can only be addressed with a more advanced 3D model able to capture the full dispersive effect of propagation over the Ninety East Ridge on the waveform morphology, which is beyond the scope of this study. We can, however, address option 2 by examining the ray paths between the satellite observations and the margin.

\subsubsection{Back-Projection of the Lead Wave Midpoint}

Here, and in Sect. 5, we will discuss the backprojection of multiple observation points from the satellite tracks, but first it is informative to consider the ray paths of just one observation point from each satellite. For this we choose a point in the middle of the lead wave. For Jason-1, this is the trough that separates the two peaks. For TOPEX, we choose a point that is the same fractional distance between the initial uplift and final down drop as the trough is between the Jason-1 observations of uplift and down drop. Figure 2 shows the locations of the observation points that are back-projected $(2 \mathrm{j}$ and $2 \mathrm{t}$ ) and their respective ray paths. The ray paths in Fig. 2 were initially evenly distributed over a range of angles, with $\Delta \theta_{0}=1^{\circ}$, and the path curvature clearly illustrates that the bathymetry of the Ninety East Ridge affects the ray trajectories and can cause information from one portion of the margin to focus in one area over another.

The ray path terminations (RPTs) are the final locations of the ray paths after the appropriate amount of travel time. The RPTs differ for the two satellite observation points due to convergence 
patterns that result from propagation over the Ninety East Ridge (Fig. 2). The Jason-1 ray paths cluster near the epicenter, while very few of the ray paths for TOPEX terminate in this area. Instead, the TOPEX ray paths terminate to the north and south of the epicenter, although the southern clustering is not meaningful since the earthquake did not reach this part of the margin. This difference in clustering suggests a complex wave propagation over the ridge and may mean that the two satellites observed a lead wave uplift pattern that originated from different locations.

We clarify that we are not suggesting that the lead wave is only the result of areas in which there is clustering; the lead wave is an effect of the margin uplift in all areas where there are RPTs. The density of the RPTs is a measure of the ability of a source in a given area to affect the lead wave. If there are ten times as many RPTs in area A than area B, the uplift must be ten times larger in area B to produce the same lead wave as an uplift in area A.

\subsubsection{Back-Projection of the Lead Wave Endpoints}

Thus far, we have only examined the back-projection of one point in the tsunami lead wave. We also consider the two points that define the initial uplift (defined as a sea surface height (SSH) of $10 \%$ of the peak height) and the final dip below mean SSH. The wavelength of the TOPEX lead wave is $\sim 600 \mathrm{~km}$ and the wavelength of the Jason-1 peaks are $\sim 240$ and $\sim 380 \mathrm{~km}$. For these wavelengths, the phase and group speeds differ by less than $0.4 \%$, so they are effectively non-dispersive (Fig. 3). Therefore, we can apply the back-projection to the points that demarcate the limits of the lead wave above mean SSH and not just the peaks which travel at the group velocity.

In Fig. 4, we report the RPTs of the six points as dots denoting the final locations of the ray paths rather than showing the full ray paths. By only examining the RPT locations, we can consider many more initial ray paths per angle and visualize more observation points in the same figure. From the ray paths of Fig. 2 and the resulting clustering of RPTs (Fig. 4b, c), it is clear that the Jason-1 satellite is sensitive to the area of the margin west of the epicenter, while TOPEX is not. In very well sampled areas, the clustering of RPTs can

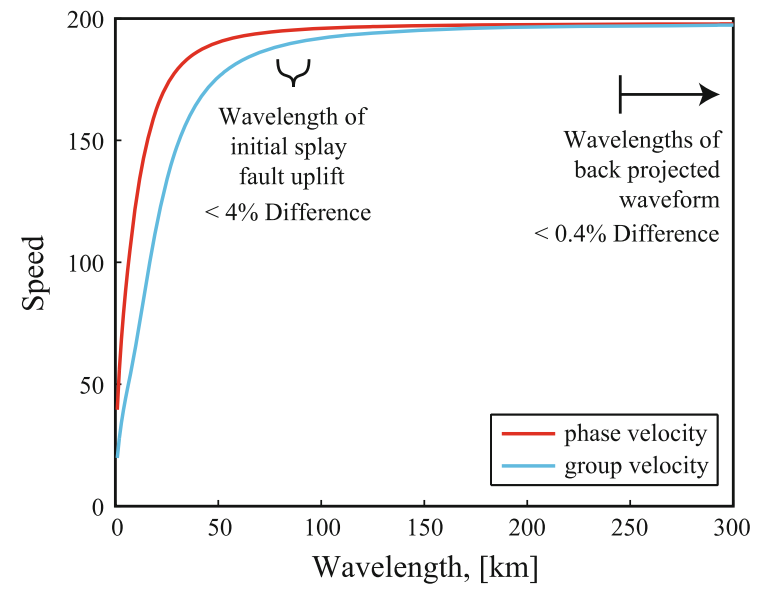

Figure 3

In the long wavelength limit the phase and group velocities are identical. For the wavelengths that characterize the lead wave of the Jason- 1 and TOPEX observations (240-600 km), the phase and group velocities differ by less than $0.4 \%$, making the features of the lead wave effectively non-dispersive

be so tight as to coalesce into what appears, to the eye, to be a continuous line.

Comparing the clustering of the two satellites shows that the tight regions are mainly non-overlapping. From this, we conclude that the signals seen by the satellites should have been influenced by seafloor uplift patterns in different parts of the margin. We see that Jason-1 is more sensitive to the southern portion of the margin (in the area of the epicenter), while TOPEX is more sensitive to the northern section (due east of the tip of northern Sumatra). Waves traveling from the epicentral area will refract towards the Jason-1 transect, and waves traveling from further to the north will refract towards the TOPEX transect. Therefore, a difference in the along-strike rupture characteristics, is compatible with the discrepancy between the satellite signals. As we will discuss in the following section, the double peak observed by Jason-1 is consistent with rupture of a splay fault in this southern section, but the sensitivity difference between the satellites suggests that there is no splay fault to the north.

Smoothing the seafloor was a necessary step in this procedure, but it alters the ray paths. In Fig. 5, we illustrate how the degree of smoothing affects the ray path trajectories. We smooth the seafloor using a filter of the form $1 / \cosh k H_{\mathrm{f}}$. A larger value for $H_{\mathrm{f}}$ 


\section{(a) Back Projected Points}

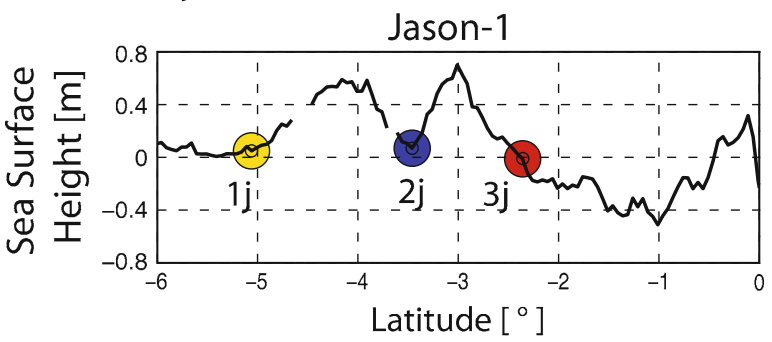

(b) Jason-1

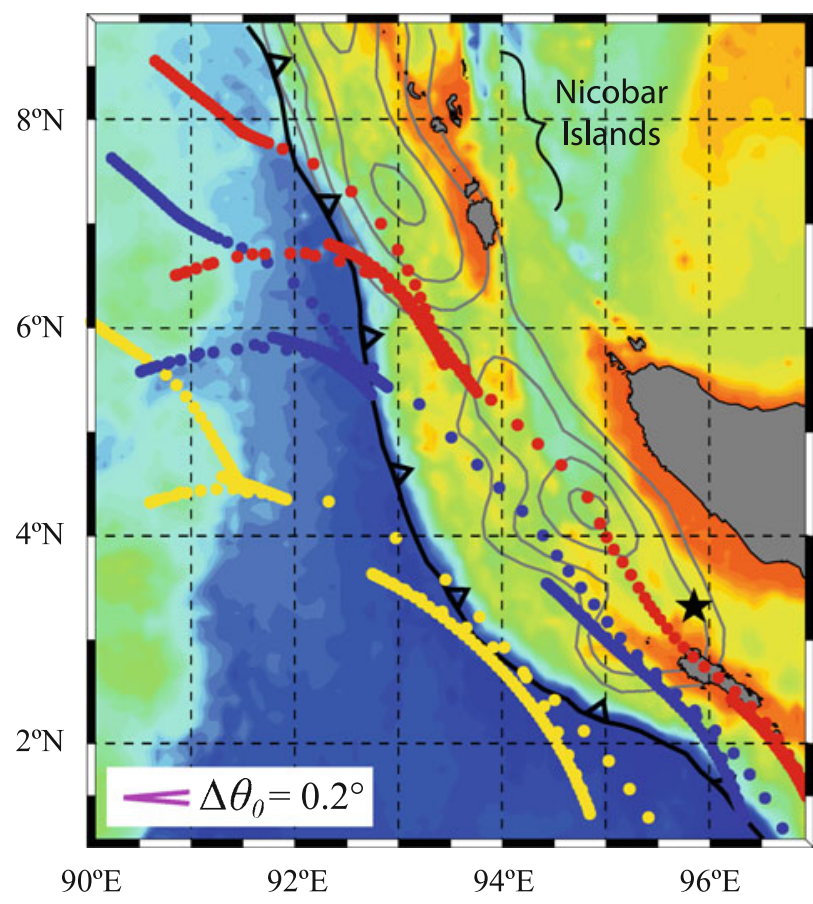

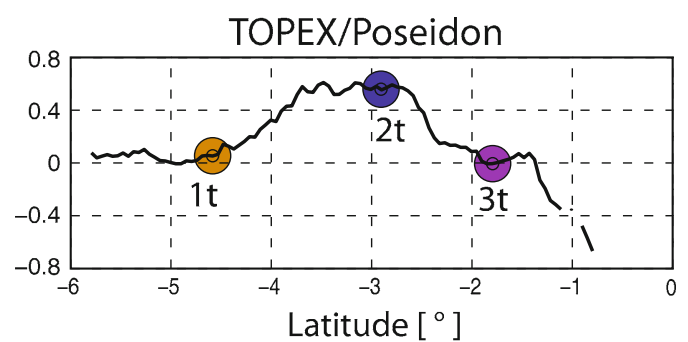

(c) TOPEX-Poseidon

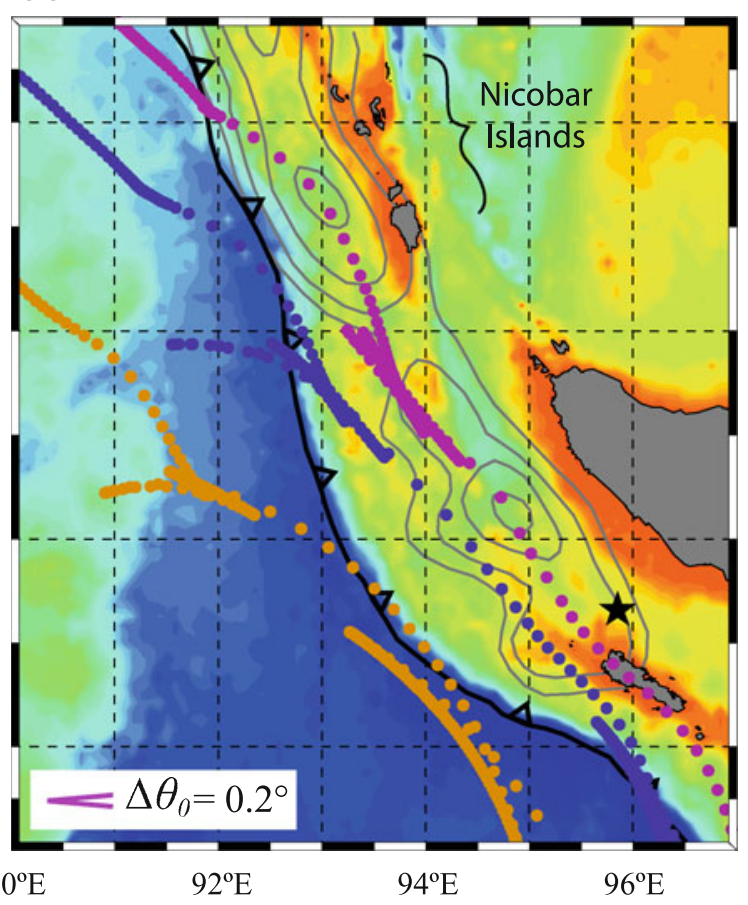

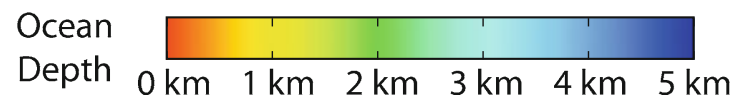

Figure 4

Back-projection of the tsunami waveform data from both the Jason-1 and TOPEX satellites. a Points of the satellite signals which are backprojected. Color of the point corresponds to the color of the RPT in $\mathbf{b}$ and $\mathbf{c}$. b RPTs of the Jason-1 points. Colored lines are not actually lines, but rather a dense collection of points. Black star is the epicentral location. Slip distribution shown is from CHLIEH et al. (2007) with $5 \mathrm{~m}$ contour levels. c TOPEX RPTs

results in a smoother seafloor, and the shape of the filter can be seen in Fig. 5a. With a minimum amount of smoothing, $H_{\mathrm{f}}=4 \mathrm{~km}$, many rays are strongly diffracted and do not approach northern Sumatra (Fig. 5b). For this filter, the assumption that $\lambda<\lambda_{\text {bath }}$ does not hold and the ray tracing procedure is not valid. In the fully smoothed limit, the rays will not be diffracted and will travel radially from their origin
(Fig. 5f is still far from this limit). We feel that $H_{\mathrm{f}}=36 \mathrm{~km}$ strikes a good balance between preserving the seafloor characteristics and smoothing the seafloor enough that the slowly varying bathymetry assumption holds for the $\lambda \sim 100 \mathrm{~km}$ wavelength that is of interest here. Also, as $H_{\mathrm{f}}$ is increased further, to $H_{\mathrm{f}}=48 \mathrm{~km}$, the results do not change significantly. 
(a)

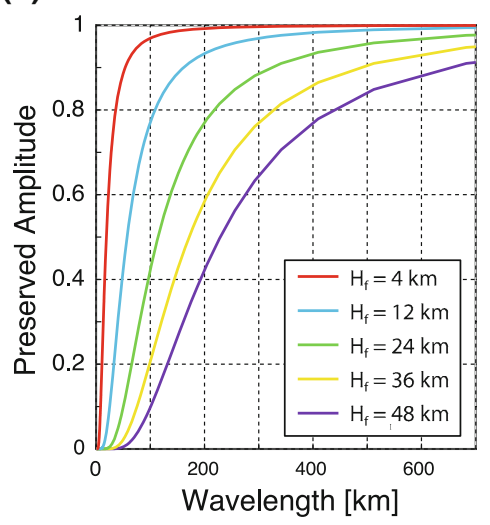

(d)

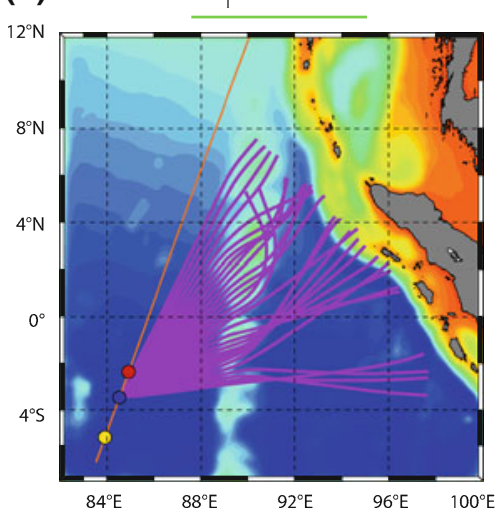

(b)

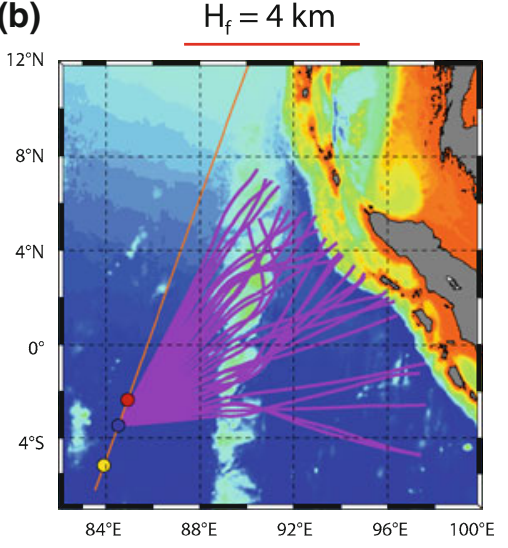

(e)

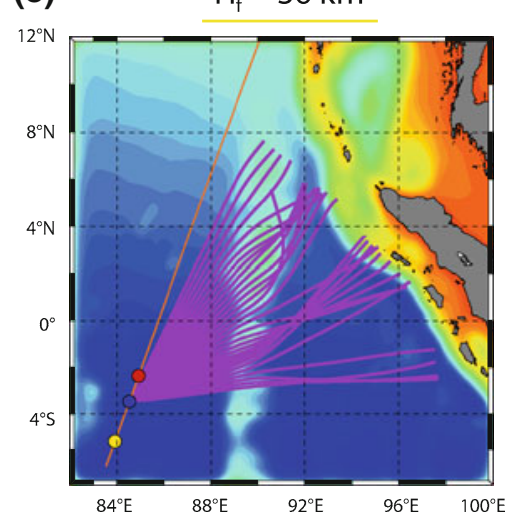

(c) $\quad H_{\mathrm{f}}=12 \mathrm{~km}$

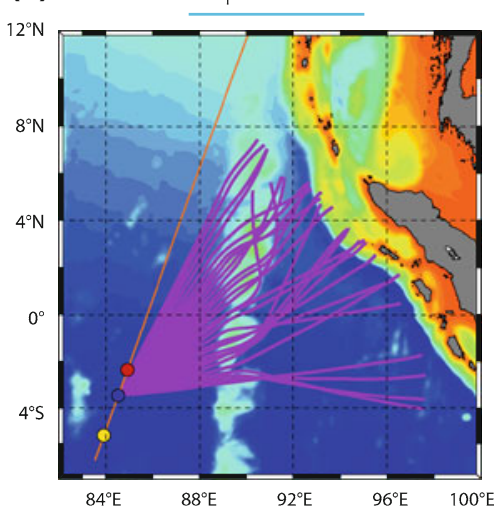

(f)

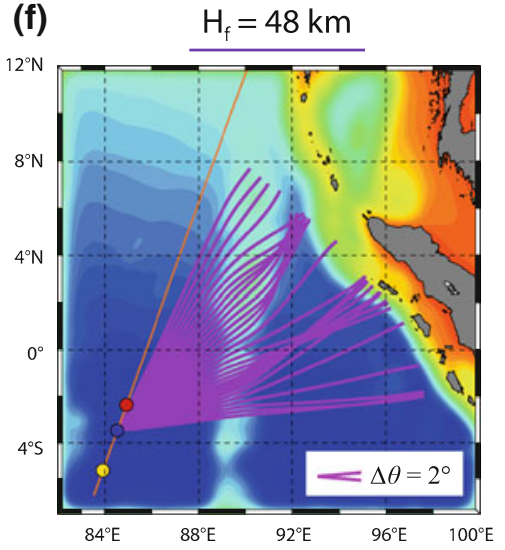

Figure 5

The back-projected paths depend on the the smoothing of the seafloor. a The shape of the filter used to smooth the seafloor. b-f The backprojected ray traces using a progressively smoother seafloor. The bathymetry in each panel is shown with the relevant amount of smoothing

\section{Exact Gravity Wave Solution and Modeling (for Uniform Depth)}

In the previous section, we showed that the satellite discrepancy may be the result of a path effect. The seafloor bathymetry refracts long wavelength waves such that the two satellites are sensitive to different parts of the margin. Now we investigate the possibility that a splay fault, located only in the southern region, resulted in the doubly-peaked lead wave. For that, we use a model for gravity wave propagation to determine the effect of splay fault rupture on the open ocean tsunami waveform. We also use this model to determine if along-strike variations in slip, not including a splay fault rupture to the south, could have resulted in the double peak that was observed by Jason-1.
We use two models, a 2D and a 3D model, to simulate the waveform due to slip on a generic splay fault and the full Sumatra margin, respectively. The 2D model (horizontal, $x$, and depth, $z$ ) represents an uplift profile that is uniform in $y$, so uplift can only vary with respect to one horizontal coordinate. The 3D model has two horizontal dimensions, $x$ and $y$, as well as the depth dimension, $z$, and can thus be used to investigate the waveform due to slip during the Sumatra-Andaman event.

\subsection{Fault Models}

The simple 2D model we use is not necessarily specific to any given subduction zone. It consists of two planar faults (Fig. 6a), which represent the subduction interface and splay fault and dip at $8^{\circ}$ 
(a) 2D Model Setup

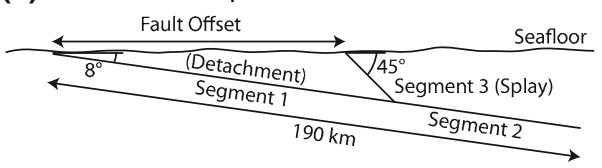

(b) 3D Fault Model Setup

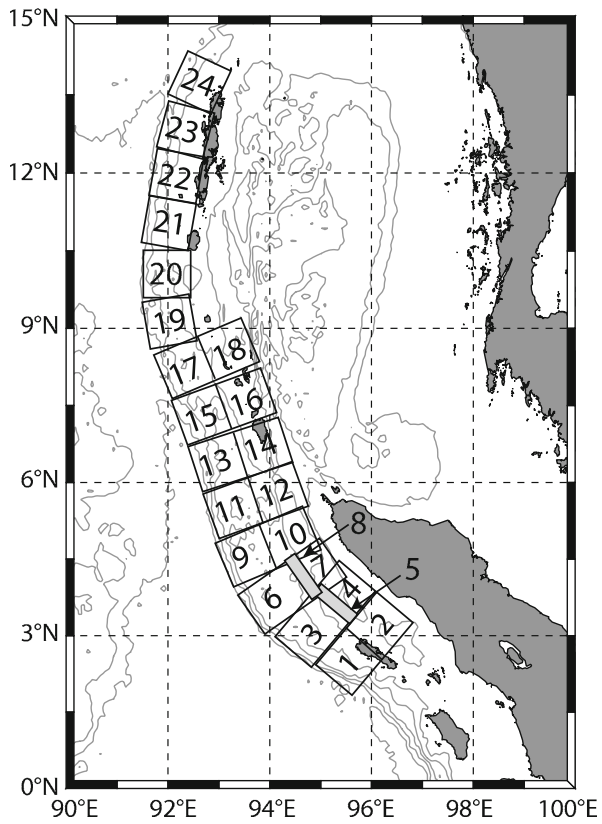

Figure 6

a Fault model geometry for 2D tsunami propagation. b Fault setup for 3D tsunami propagation. Segments 5 and 8 are steeply dipping splay faults. Details of fault segment locations given in Table 1

and $45^{\circ}$, respectively. An $8^{\circ}$ dip is reasonable for the Sumatra subduction interface (e.g., Tsai et al., 2005; ENGDAHL et al., 2007), but the choice of a $45^{\circ}$ dip for the splay fault is unconstrained. The subduction interface is divided into updip (segment 1) and downdip (segment 2) segments by the intersection of the splay fault and the subduction interface. The distance between the surface expression of these two faults is the fault offset, and a value of $110 \mathrm{~km}$ is used. A constant amount of slip is prescribed on segment 2, $15.5 \mathrm{~m}$ (BANERJEE et al., 2007), and varying amounts of slip are prescribed on segments 1 and 3 so that the same $M_{0}$ is released for each scenario, although not the same moment tensor since the faults have different dips. This is calculated from the sum of the moment tensors for each of the three fault segments (strictly dip-slip motion on each segment) and is equal to the case of $15.5 \mathrm{~m}$ of slip on both segments 1 and 2 and none on the splay.

The geometry considered here has a $37^{\circ}$ angle between main fault and the splay fault. Studies of fault branch activation (KAME et al., 2003; DeDonTNEY, 2011) indicate that with this geometry the splay fault is unlikely to be activated. However, the simplified geometry shown in Fig. 6 is unlikely to be an accurate representation. If the transition from segment 2 to segment 3 is gradual, rather than abrupt as shown, the angle between the two faults is much smaller at the intersection. The studies of Kame et al. (2003) and DeDontney (2011) show that for a small angle of intersection, the splay fault is likely to be activated. These studies show that the co-activation of both the splay fault and the updip portion of the subduction interface does not always occur, but can occur for a variety of initial conditions.

Seafloor deformation is determined by assuming an elastic, homogenous and isotropic half space and using the method developed by OKADA (1985) to implement the appropriate elasticity solutions and solve for seafloor deformation. While we acknowledge (and later discuss) that downdip variations in slip affect the seafloor uplift, unless otherwise stated, uniform slip is applied to each of the faults, and we assume that slip propagates to the seafloor, creating a discontinuity.

The 3D model we use is specific to the Sumatra geometry. This fault model consists of 24 subfaults (Fig. 6b and Table 1), modified from FusI and SATAKe (2007), each of which measure $100 \mathrm{~km}$ downdip, except in the vicinity of the splay faults, where the splay fault intersection divides the two subfaults, as in the 2D model. The two splay fault segments have a fault offset of $125 \mathrm{~km}$ from the subduction interface segments and measure $38 \mathrm{~km}$ downdip. This is a larger offset than we later propose as a potential splay fault location because the model does not account for the slow tsunami wave propagation over the shallow accretionary prism. Sea surface uplift due to slip on a splay fault occurs in shallow water, where it travels more slowly than modeled here. This would act to increase the distance between the two modeled peaks, so we artificially increase the offset a priori so that the modeled peak will be in a representative location. 
Table 1

$3 D$ Fault model setup parameters

\begin{tabular}{llllcll}
\hline Fault & Strike & Dip & Length $(\mathrm{km})$ & Time $(\mathrm{s})$ & Lat & Lon \\
\hline 1,2 & $310^{\circ}$ & $8^{\circ}$ & 100,100 & 0 & $1.85^{\circ}$ & $95.60^{\circ}$ \\
3,4 & $310^{\circ}$ & $8^{\circ}$ & 154,56 & 0 & $2.38^{\circ}$ & $94.80^{\circ}$ \\
5 & $310^{\circ}$ & $45^{\circ}$ & 38 & 0 & $3.25^{\circ}$ & $95.53^{\circ}$ \\
6,7 & $325^{\circ}$ & $8^{\circ}$ & 154,56 & 50 & $3.04^{\circ}$ & $93.90^{\circ}$ \\
8 & $325^{\circ}$ & $45^{\circ}$ & 38 & 50 & $3.69^{\circ}$ & $94.83^{\circ}$ \\
9,10 & $333^{\circ}$ & $8^{\circ}$ & 100,100 & 100 & $3.95^{\circ}$ & $93.30^{\circ}$ \\
11,12 & $340^{\circ}$ & $8^{\circ}$ & 100,100 & 150 & $4.90^{\circ}$ & $93.00^{\circ}$ \\
13,14 & $342^{\circ}$ & $8^{\circ}$ & 100,100 & 200 & $5.82^{\circ}$ & $92.68^{\circ}$ \\
15,16 & $340^{\circ}$ & $8^{\circ}$ & 100,100 & 250 & $6.72^{\circ}$ & $92.38^{\circ}$ \\
17,18 & $337^{\circ}$ & $8^{\circ}$ & 100,100 & 300 & $7.64^{\circ}$ & $92.08^{\circ}$ \\
19 & $350^{\circ}$ & $8^{\circ}$ & 100 & 350 & $8.60^{\circ}$ & $91.64^{\circ}$ \\
20 & $0^{\circ}$ & $8^{\circ}$ & 100 & 400 & $9.60^{\circ}$ & $91.51^{\circ}$ \\
21 & $10^{\circ}$ & $8^{\circ}$ & 100 & 450 & $10.66^{\circ}$ & $91.48^{\circ}$ \\
22 & $10^{\circ}$ & $8^{\circ}$ & 100 & 500 & $11.56^{\circ}$ & $91.63^{\circ}$ \\
23 & $15^{\circ}$ & $8^{\circ}$ & 100 & 550 & $12.51^{\circ}$ & $91.78^{\circ}$ \\
24 & $25^{\circ}$ & $8^{\circ}$ & 100 & 600 & $13.51^{\circ}$ & $92.01^{\circ}$ \\
\hline
\end{tabular}

Multiple faults on one line are the updip and downdip sections of a planar fault segment. All faults are $100 \mathrm{~km}$ wide (along-strike) and length is the downdip dimension

A $2 \mathrm{~km} / \mathrm{s}$ along-strike rupture velocity is approximated by different activation times for the subfaults (denoted "Time" in Table 1). We choose this velocity as a compromise between the fast rupture velocities of seismic inversions (Амmоn et al., 2005; IsHi et al., 2005; LAY et al., 2005) and the slow propagation that tsunami models prefer (FuJII and SATAKe, 2007; GRILLI et al., 2007). We also include a rise time of $60 \mathrm{~s}$ (slip accumulates as a ramp function over the specified time interval) because most energy, in a given location, was released in this timespan during the Sumatra-Andaman event (Kiser and Ishii, personal communication). As the rise time increases, the waveform can lose the signature of a double peak, so we use $60 \mathrm{~s}$ as an upper bound on the rise time.

We compare four models of slip distribution that represent the slip during the earthquake. Each of these has comparable seismic moment release (Table 2) and is influenced by a variety of published slip inversions (Chlien et al., 2007; BANerJee et al., 2007; FujII and SATAKE, 2007). Our first goal is to determine if a splay fault of limited along-strike extent can lead to the double peak observed by Jason-1. We consider two models, A and C, that do not have slip on a splay fault, and two models, B and D, that do include slip on a splay fault. As in the 2D case, when slip occurs on the
Table 2

Fault slip (m) for the four 3D models

\begin{tabular}{|c|c|c|c|c|}
\hline & A & B & $\mathrm{C}$ & $\mathrm{D}$ \\
\hline 1 & 3 & - & - & - \\
\hline 2 & 10 & - & - & - \\
\hline 3 & 20 & 17.8 & 15 & 13.5 \\
\hline 4 & 27 & - & 19 & - \\
\hline 5 & 0 & 21 & 0 & 15 \\
\hline 6 & 25 & 23.4 & 21 & 20 \\
\hline 7 & 30 & - & 25 & - \\
\hline 8 & 0 & 17 & 0 & 11 \\
\hline 9 & 22 & - & 16 & - \\
\hline 10 & 18 & - & 14 & - \\
\hline 11 & 12 & - & 15 & - \\
\hline 12 & 8 & - & 10 & - \\
\hline 13 & 7 & - & 13 & - \\
\hline 14 & 5 & - & 11 & - \\
\hline 15 & 8 & - & 15 & - \\
\hline 16 & 6 & - & 13 & - \\
\hline 17 & 5 & - & - & - \\
\hline 18 & 4 & - & - & - \\
\hline 19 & 5 & - & - & - \\
\hline 20 & 5 & - & - & - \\
\hline 21 & 3 & - & - & - \\
\hline 22 & 3 & - & - & - \\
\hline 23 & 1 & - & - & - \\
\hline 24 & 2 & - & - & - \\
\hline$M_{0}$ & $6.85 \mathrm{e} 22$ & $6.87 \mathrm{e} 22$ & $6.84 \mathrm{e} 22$ & $6.86 \mathrm{e} 22$ \\
\hline
\end{tabular}

- Indicates that there in no change in slip amount from the previous. Models A and B have one area of high uplift (off the coast of N. Sumatra) while models $\mathrm{C}$ and $\mathrm{D}$ have two areas (Nicobar Islands and N. Sumatra). Models A and C do not have a splay fault, while models B and D do have a splay fault

splay, there is less slip on the updip detachment segment. The second goal of this 3D model is to determine if the second peak could be due to a region of high slip further along-strike. To examine that, we use two models, A and B, with one area of high slip, off the coast of northern Sumatra, and two models, C and D, that have two areas of high slip, one off the coast of northern Sumatra and one near the Nicobar Islands (BANERJEe et al., 2007; CHLIEH et al., 2007). We thus consider a total of four models, one for each combination of slip area and splay fault existence, to evaluate which factors can cause a double peak.

\subsection{Exact Hydrodynamics with Dispersion, but for a Uniform Depth}

For this study we are primarily concerned with wave propagation across the open ocean and, 
principally because exact linearized hydrodynamic calculations can be done for that case, we assume a uniform ocean depth, $H=4 \mathrm{~km}$. As is well known (e.g., Lamb, 1932; Batchelor, 1967; Milne-Thomson, 1968), the Euler equations of motion for a uniform inviscid and incompressible fluid, initially at rest, can be solved for velocity $\vec{u}$ in terms of a harmonic velocity potential $\phi=\phi(x, z, t)$ for our $2 \mathrm{D}$ modeling, or $\phi(x, y, z, t)$ for 3D modeling, with $\vec{u}=\nabla \phi$.

We first discuss the 2D case (see Appendix for a complete discussion). By solving the Laplace equation with linearized boundary conditions, we can determine the sea surface uplift, $\eta(x, t)$, given a sudden uplift of the seafloor, $\zeta_{0}(x)$, as (KAJIURA, 1963)

$$
\eta(x, t)=\frac{1}{2 \pi} \int_{-\infty}^{\infty} \frac{\tilde{\zeta}_{0}(k) \mathrm{e}^{i k x} f(k, t)}{\cosh (k H)} \mathrm{d} k
$$

where $k$ is the wavenumber, $\tilde{\zeta}_{0}(k)$ is the Fourier transform of the sudden seafloor uplift at $t=0$, and $f(k, t)$ is the wave translation defined as

$$
f(k, t)=\cos [k c(k) t]=\frac{1}{2} \mathrm{e}^{i k c(k) t}+\frac{1}{2} \mathrm{e}^{-i k c(k) t}
$$

where $c(k)$ is the wave speed. Half of each Fourier uplift component propagates with speed $c(k)$ in the positive and negative $x$ directions, respectively. Note that $\tilde{\zeta}_{0}(-k)$ is the complex conjugate of $\tilde{\zeta}_{0}(k)$.

This leads to our numerical modeling procedure which starts with representing any sudden seafloor uplift to acceptable accuracy as a finite Fourier series.

$$
\zeta_{0}(x)=\sum_{m=-M / 2}^{M / 2} \frac{A_{m} \mathrm{e}^{i k_{m} x}}{\Lambda_{M m}}
$$

where $M$ is a sufficiently large even integer and

$$
k_{m}=\frac{2 \pi m}{L} \text { and } \begin{aligned}
\Lambda_{M m} & =1+\delta_{\frac{M}{2}|m|} \\
& = \begin{cases}2, & \text { if }|m|=M / 2 \\
1, & \text { otherwise }\end{cases}
\end{aligned}
$$

Here $A_{m}$ is the complex conjugate of $A_{-m}$ and $A_{0}$ is real, as is $A_{ \pm M / 2}$. The $A_{m}$ are determined by doing a Fast Fourier Transform (FFT) on the sudden seafloor uplift, obtained from the elastic uplift distribution of the fault model, and the period $L$ of the series is taken much larger than the spatial domain of interest, so that artifacts from the periodic replication of the desired uplift pattern do not propagate into the region of interest over times of interest.

Imposition of the sudden seafloor uplift $\zeta_{0}(x)$ causes a corresponding impulsive initial sea surface uplift $\eta(x, t=0)$ which is expressed by writing the same Fourier series as in Eq. 5 but with each $A_{m}$ now replaced by $A_{m} / \cosh \left(k_{m} H\right)$ (KaJiura, 1963). This decreases the amplitudes of higher frequency components and correctly captures how a discrete seafloor uplift will affect the sea surface. This factor is used by some wave propagation models (e.g., Hino et al., 2001), but differs from models of tsunami propagation that translate the seafloor deformation exactly to the sea surface (e.g., Grilli et al., 2007; SLAdEN and Hebert, 2008).

Then the subsequent sea surface disturbance $\eta(x, t)$ for all $t$ and $x$ considered can be exactly represented by

$$
\eta(x, t)=\sum_{m=-M / 2}^{M / 2} \frac{A_{m} \mathrm{e}^{i k_{m} x} f\left(k_{m}, t\right)}{\Lambda_{M m} \cosh \left(k_{m} H\right)}
$$

where

$$
c\left(k_{m}\right)=\sqrt{\frac{g}{k_{m}} \tanh \left(k_{m} H\right)}
$$

Note that by Eq. 4 the $f\left(k_{m}, t\right)$ propagate half of each corresponding Fourier component forward, and half backward, at its respective phase speed.

The Jason-1 track data indicate that the waves are dispersive (Kulikov and Medvedev, 2005), so we compare the results of linear wave propagation using shallow water theory $(c=\sqrt{g H})$ to those that include exact wave dispersion $(c(k)=\sqrt{g \tanh (k H) / k})$. We also note that some numerical methods use the approach of ImAmuRA et al. (1988), which uses the shallow-water approximation but matches errors of the numerical procedure to the first term of the expansion of the dispersive wave speed, in the spirit of Boussinesq models. This procedure is only accurate for a specified combination of time step, grid spacing and depth. We checked this using the COMCOT program (WANG and LiU, 2006), which uses this methodology, and find that it does approximately match the results of our exact 2D modeling of wave morphology over a constant depth, but it will 
not exactly capture the dispersive process over variable ocean depths.

The approach is extended to $3 \mathrm{D}$ by replacing $k$ with $|k|=\sqrt{k_{x}^{2}+k_{y}^{2}}$ in the wave propagation, calculating a two-dimensional Fourier transform and integrating over $k_{x}$ and $k_{y}$. This leads to the finite Fourier series numerical modeling representation

$$
\eta(\vec{x}, t)=\sum_{m=-M / 2}^{M / 2} \sum_{n=-N / 2}^{N / 2} \frac{A_{m, n} \mathrm{e}^{i \vec{k}_{m, n} \cdot \vec{x}} f\left(\left|\vec{k}_{m, n}\right|, t\right)}{\Lambda_{M m} \Lambda_{N n} \cosh \left(\left|\vec{k}_{m, n}\right| H\right)}
$$

Here $\vec{k}_{m, n}=\left[2 \pi m / L_{x}, 2 \pi n / L_{y}\right]$, where $L_{x}$ and $L_{y}$ are the respective $x$ and $y$ direction periods of the Fourier series, and $M$ and $N$ are sufficiently large even integers. The same guidelines are used in selecting $L_{x}, L_{y}, M$ and $N$ as stated above for the 1D FFT. The $A_{m, n}$ are determined by doing a 2D FFT of $\zeta_{0}(x, y)$,

$$
A_{m, n}=\sum_{p=0}^{M-1} \sum_{q=0}^{N-1} \frac{\mathrm{e}^{-2 \pi i\left(\frac{p m}{M}+\frac{q n}{N}\right)}}{M N} \zeta_{0}\left(\frac{p L_{x}}{M}, \frac{q L_{y}}{N}\right)
$$

Because the expression defines $A_{-m,-n}$ as the complex conjugate of $A_{m, n}$, and $k_{m, n}=-k_{-m,-n}$, it is clear that the above finite Fourier series for sea surface uplift $\eta(\vec{x}, t)$, in Eq. 9 always sums to a real value.

In our case, the 2D FFT is performed in a Cartesian space with grid spacings $L_{x} / M=L_{y} /$ $N=0.8 \mathrm{~km}$. The 1D FFT version of the modeling (for which the sums over $n$ and $q$ in Eqs. 9-10 are deleted) is employed with a grid spacing of $0.6 \mathrm{~km}$. The Cartesian assumption is a valid approximation because the modeled domain is much smaller than Earth's radius.

\subsection{Results from Gravity Wave Propagation}

This exact model informs us of two significant effects: (1) the co-activation of the subduction interface and a splay fault can result in a doublypeaked lead wave, while variations in along-strike slip distribution on a single fault plane cannot, and (2) dispersion plays a pivotal role in the waveform morphology and arrival time. This second point is important because we find that accounting for dispersion allows signal to travel faster than would be indicated by the SWWS, and this has important implications for our ray tracing procedure (see Sect. 5).

\subsubsection{Important Effect of Dispersion on First Arrival Time}

It is generally assumed that the SWWS is the upper bound to velocities and that no signal can travel ahead of this, but this is not true for dispersive wave travel. The formulation of Sect. 4.2 exactly captures the effect of dispersion, and Fig. 7 shows the inadequacies of this assumption. We illustrate how a dispersive wave front evolves and results in disturbances ahead of the non-dispersive wave front. We examine the sea surface response to an initial boxcar uplift of the sea surface of $2 \eta_{0}$. This was achieved by using the formulation outlined above, but with the $1 / \cosh (k H)$ term removed from Eq. 7 and the $A_{m}$ are determined from a FFT on the sea surface. With the non-dispersive shallow-water model, this causes a surface uplift $\eta_{0}$ propagating in the $-x$ direction. After $2 \mathrm{~h}$ of travel time, with $H=4 \mathrm{~km}$, the dispersive sea surface uplift is ahead of the shallow water wave front. This uplift is greater than $10 \%$ of $\eta_{0}$ up to $22 \mathrm{~km}$ ahead of the shallow-water wave front, and some uplift extends further than this.

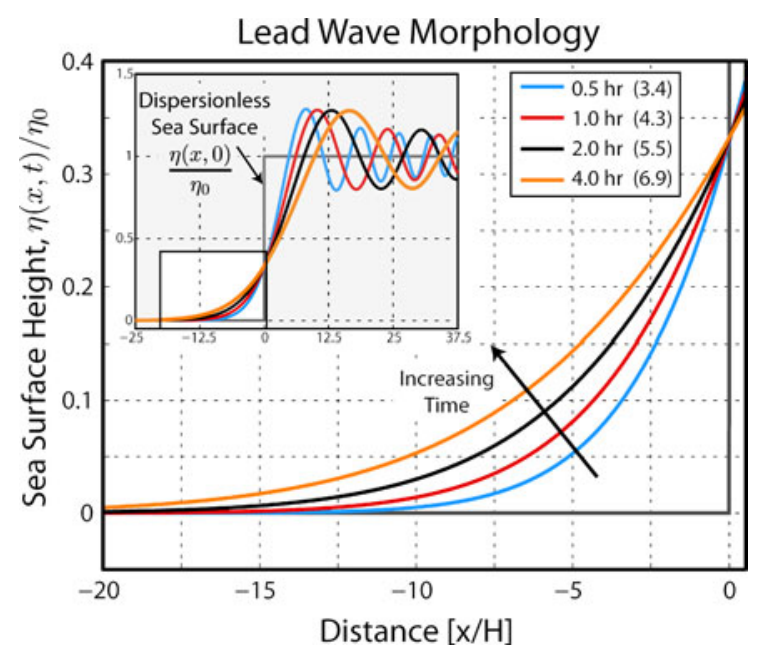

Figure 7

Exact sea surface uplift in response to an initial boxcar uplift of the surface of $2 \eta_{0}$. With the non-dispersive shallow-water model, this causes a surface uplift $\eta_{0}$ propagating in the $-x$ direction (shown in inset), for increasing time. A reference frame is adopted with the origin moving at the SWWS, $\sqrt{g H}$, with $H=4 \mathrm{~km}$. Additional legend information: quantity in parentheses is the dimensionless distance, $x / H$, ahead of the shallow water wave front, where uplift is $10 \%$ of $\eta_{0}$. This distance may be shown to be proportional to $(\sqrt{g H} t / H)^{1 / 3}$ when $\sqrt{g H} t \gg H$ 
This is not an artifact due to series truncation (curves are invariant as higher wave numbers are included), but rather a real feature of the differential equation that governs this system. While it may at first seem remarkable that signal can travel faster than the maximum phase and group velocities of the gravity waves, we must keep in mind that a fuller formulation for a compressible fluid would also have an acoustic mode traveling far faster $(\sim 1,500 \mathrm{~m} / \mathrm{s})$ than the SWWS. Here we have simply made the standard assumption that the fluid can be treated as incompressible and the acoustic wave speed has gone to infinity. But, the fact that this fast acoustic wave speed exists should be a hint that we should not be alarmed if signal can travel faster than the fastest gravity wave disturbance.

The shallow-water model, which does not include dispersion, does not describe the evolving wave morphology and only approximates the arrival time of a wave. Therefore, the tsunami will arrive at a given observation point earlier that would be indicated by the SWWS, although the maximum amplitude part of the waveform will travel slower than the SWWS. This leads to a small correction to our ray tracing procedure to properly interpret the back-projection results of the initial tsunami uplift (points $1 \mathrm{j}$ and $1 \mathrm{t}$ ). This correction shifts the RPTs

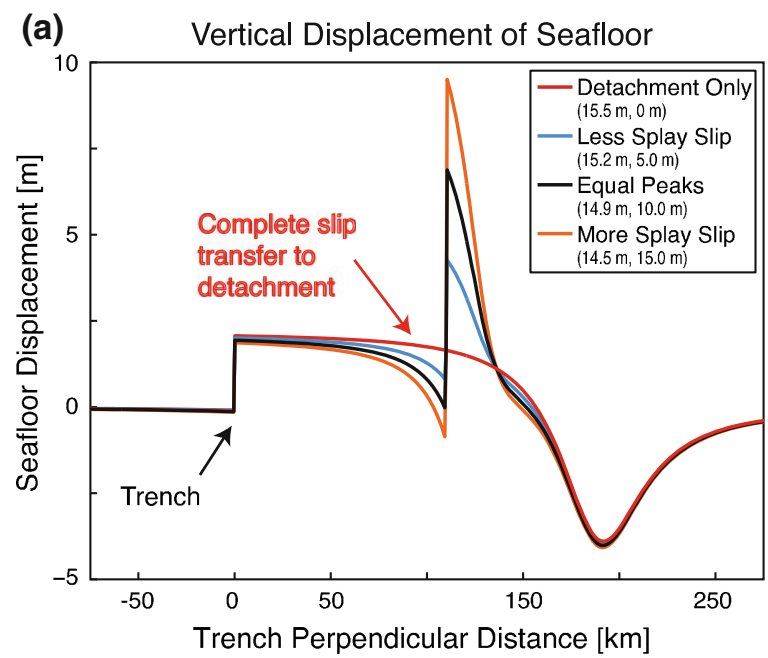

further towards the shore and will be discussed thoroughly in Sect. 5 .

\subsubsection{Shape of Tsunami Waveform Due to Slip on a Splay Fault}

The $2 \mathrm{D}$ results (Fig. 8) show that when dispersion is included, slip on both the detachment and a splay fault can lead to a doubly-peaked waveform. The shape of the waveform depends on the relative slip partitioning between the splay fault and the detachment fault. Figure 8a shows the seafloor deformation for the case of slip on just the subduction interface (segments 1 and 2), and for varying amounts of slip on the splay fault, segment 3. These are shown for instantaneous, simultaneous, uniform slip accumulation on all three fault segments (in Sect. 5 we discuss the effect of this assumption on the waveform).

When slip occurs solely on the subduction interface, there is only one area of seafloor uplift, but there is a small second peak in the waveform due to the dispersion relation (Fig. 8b). The short wavelength components needed to capture the discrete uplift at the trench travel more slowly than the long wavelength components. This leads to a second peak, substantially smaller than the first peak of the lead (b)

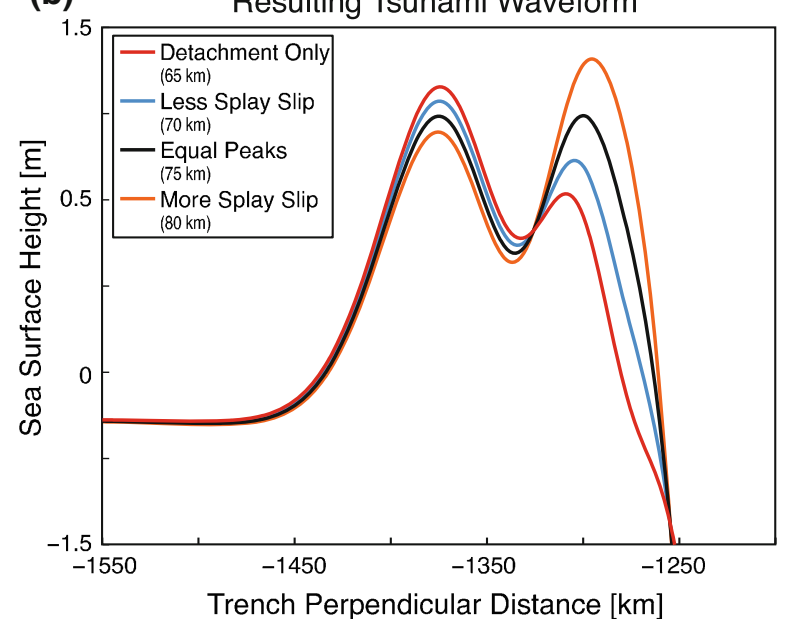

Figure 8

a 2D model of vertical seafloor displacement due to slip on just the detachment (red), or a combination of the slip on both faults. b Sea wave resulting from seafloor displacements after $2 \mathrm{~h}$ of dispersive propagation in a 2D model. Distance is measured perpendicular to the wavefront, where the trench is located at the origin. Slip on both faults results in a doubly-peaked lead wave, similar to that observed by the Jason-1 satellite. Additional legend info: quantity in parentheses is (a) slip on segment $1(\mathrm{~m})$ and slip on segment 3 (m) (b) peak spacing 
wave, which should not be confused with the double peaks of equal amplitude observed by Jason-1.

If there is $14.9 \mathrm{~m}$ of slip on segment 1 and $10.0 \mathrm{~m}$ of slip on segment 3, there are two peaks of equal amplitude and comparable wavelength (Fig. 8b). When more or less slip occurs on the splay, the resulting waveforms have peaks of non-equal amplitude, and the spacing between the peaks increases with additional slip on the splay. The equal amplitude peaks are $75 \mathrm{~km}$ apart, which is less than the $112 \mathrm{~km}$ observed by the Jason-1 satellite, but the shallow bathymetry of the accretionary prism, and initially slow propagation of uplift due to splay fault slip, may account for this discrepancy. The bathymetry will also alter the waveform from what is modeled here due to Green's Law (e.g. Synolakis, 1991), which captures how the amplitude of a wave alters due to propagation over a sloped seafloor. For a wave propagating into progressively deeper water, the actual wave will be longer wavelength and smaller amplitude than modeled here. However, with small modifications to the amounts of slip on the two faults, equal amplitude peaks can still occur with these effects.

Only calculations that fully include the dispersion relation produce peaks of comparable amplitude and wavelength. Without the inclusion of dispersion, the propagating wave maintains the same shape as the initial sea surface uplift. With dispersion, the wave amplitude due to the splay fault uplift decreases significantly as the wave travels. Figure 9 illustrates this effect by showing both a dispersive and a nondispersive wave after $2 \mathrm{~h}$ of propagation time. Seafloor deformation due to slip on the splay fault has a shorter wavelength than that due to slip on the detachment because the splay fault is more steeply dipping than the subduction interface. This results in dispersion affecting the peaks differently, and the amplitude of the peak due to slip on the splay fault diminishes, while the amplitude of the peak due to slip on the subduction interface is mostly preserved with only its shape modified.

Figure 9 also illustrates the inadequacies of the SWWS upper bound assumption by showing that signal occurs ahead of the non-dispersive case. In the non-dispersive scenario, the original seafloor uplift at the trench results in a sea surface zero-crossing at

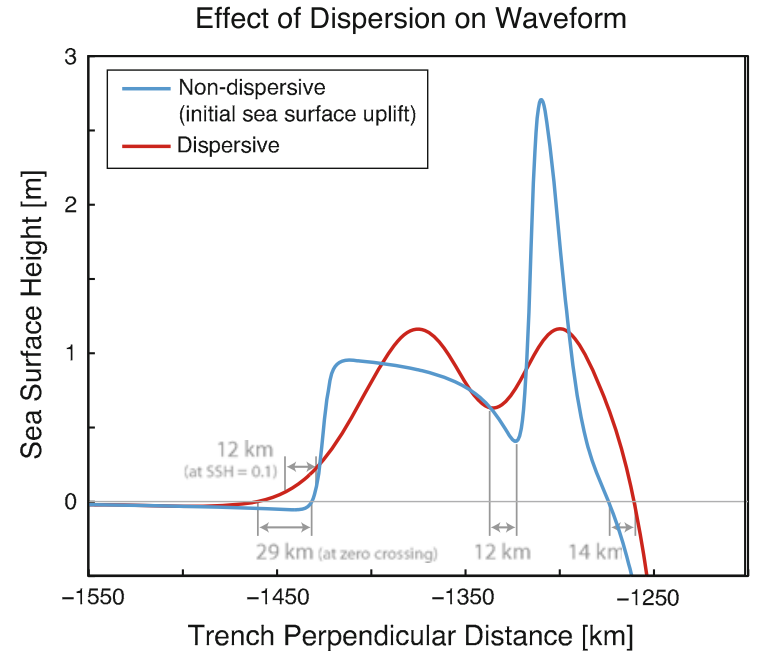

Figure 9

Dispersion significantly alters the shape of the tsunami waveform after $2 \mathrm{~h}$ of propagation. The non-dispersive line reflects the initial sea surface uplift. Two peaks of unequal amplitude and wavelength evolve into two peaks of similar form. Distances labeled show the shift in key features of the waves

$x=-1,430$. The dispersive wave clearly shows sea surface uplift extending past this point by $29 \mathrm{~km}$, to $x=-1,459$. This is due to the same effect shown in Fig. 7. If instead of considering the zero crossing, we examine the $\mathrm{SSH}$ at $10 \%$ of the initial uplift, the dispersive wave travels $12 \mathrm{~km}$ ahead of a nondispersive wave traveling at the SWWS. Figure 9 also shows how the dispersive trough and final drop below mean SSH shift relative to initial uplift patterns. The trough migrates forward, and the down-drop migrates backwards, by 12 and $14 \mathrm{~km}$ respectively, due to the dispersive waveform evolution.

Additional important parameters in determining the final waveform include the fault offset, the splay fault dip, whether the splay fault is a forethrust or a back thrust, the rise time, and the updip rupture velocity. We find that for a large and reasonable range in these parameters, it is possible to obtain a doubly-peaked waveform by altering the amount of slip partitioning. Also of significance is whether slip propagates to the trench or dies out beneath the accretionary prism. GeIST and DMOwska (1999) demonstrated the importance of dip-directed slip variations on the resulting waveform, and it is only if slip reaches the trench or close to the trench $(\sim 20 \mathrm{~km})$ that a double peak can be reproduced. 


\subsubsection{Effect of Splay Faulting on Sumatran Tsunami Waveform}

By extending the model to $3 \mathrm{D}$, we examine the effects of along-strike variations in slip on the resulting waveform and show that the second peak observed by the Jason-1 satellite could not be the result of a high-slip region in the Nicobar Islands (Chlieh et al., 2007; IshiI et al., 2005; BanerJee et al., 2007). Since this model does not include effects of the seafloor bathymetry, it is not our intention to exactly reproduce the observations, but rather to show that including slip on a splay fault produces a double peak, while high slip in the Nicobar Islands does not.

Figure 10 shows the sea surface profile along the satellite tracks for the four fault slip models investigated. Models A and C, which do not have a splay fault, but differ in their along-strike slip distributions (Table 2), cannot reproduce the Jason-1 double peak (Fig. 10a). Model A has an area of high slip off the coast of northern Sumatra, and model C has high slip in both northern Sumatra and the Nicobar Islands. Even with these differences, there is little variation between the predicted Jason-1 profiles, with respect to their ability to reproduce the second peak. Maximum wave amplitudes will radiate perpendicular to the margin, so the uplift in the Nicobar Islands is primarily sent westward, rather than to the southwest, and has little effect on the lead wave observed by the satellites.

Models B and D (analogous to models A and C but incorporating slip on a splay fault as well) have a pronounced second peak, indicating that a splay fault can create the observed morphology. The location of the initial uplift does not match the observed sea surface due to the constant depth assumption.

The TOPEX profile (Fig. 10b) is similar to the Jason-1 profile, but the small differences in space and time between the two transects lead to some significant changes. Most notably, the second peak is smaller in the TOPEX profile. The uplift signature from the splay fault, with its limited along-strike extent, is directed more towards the Jason-1 transect, even with the constant depth model assumption of straight, non-refracted ray paths. This sea surface uplift starts to fade towards the west where the TOPEX transect was made. Combining this with the refractive bathymetric effects shown in Sect. 3.2 seems to plausibly explain the differences in the
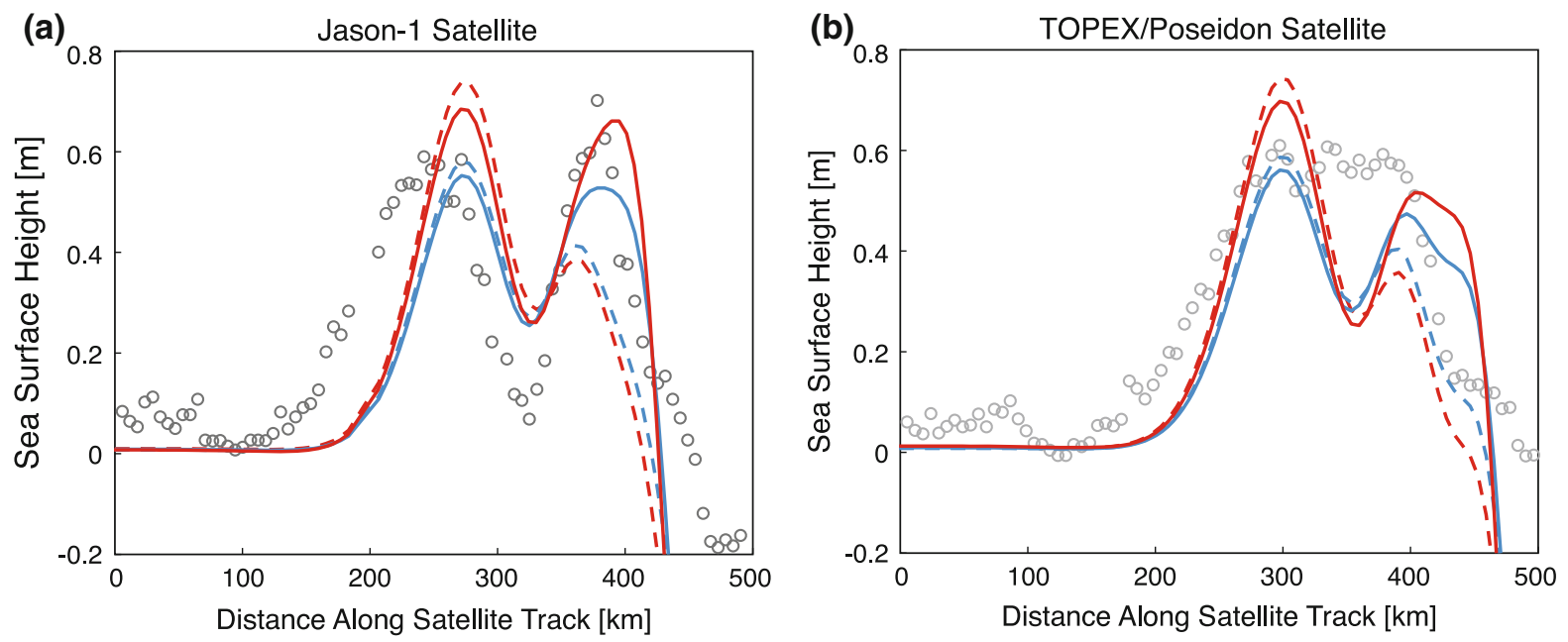

\begin{tabular}{|ll|}
\hline 0000 Jason-1 & 0000 TOPEX/Poseidon \\
$--\cdot$ A (No Splay, Low Nicobar) & $--\cdot$ C (No Splay, High Nicobar) \\
\hline B (With Splay, Low Nicobar) & D (With Splay, High Nicobar) \\
\hline
\end{tabular}

Figure 10

Results from 3D models, with or without splay fault slip and with or without significant slip near the Nicobar Islands. Data are shown (a) along the Jason-1 satellite track, and (b) along the TOPEX satellite track, with an arbitrary origin. Regardless of the slip near the Nicobar Islands, models without a splay fault do not produce comparable double peaks in the Jason-1 record 
observed signals and support the activation of a splay fault off of northern Sumatra.

\subsection{The Importance of Dispersion and Scattering}

When modeling tsunamis in the open ocean and inverting models for slip, it is important to include the effects of frequency dispersion, which determine how the waveform evolves with time and distance traveled. Even though the sea surface uplift is small compared to the ocean depth and the basic features are long wavelength, the shallow-water assumption will not accurately reflect the evolving wave morphology. The short wavelength components, like those that result from rupture propagating to the seafloor, or the uplift due to slip on a splay fault, are strongly affected by dispersion and travel more slowly across the open ocean than their long wavelength counterparts.

An advantage to the $2 \mathrm{D}$ and $3 \mathrm{D}$ models that we employ is that they exactly represent the dispersion relationship; it is clear that the doubly-peaked waveform can emerge from an initial sea surface uplift pattern that is very dissimilar to the observed waveform. But, since the dispersive wave speed is depth-dependent, a drawback to this method is the constant depth assumption. The splay fault reaches the seafloor at a shallower depth than our constant depth model assumes, and since waves travel more slowly over shallow water, the uplift due to splay fault slip will lag behind the point at which we model it. In the 3D models we account for this by an ad hoc initial placement of the splay fault further from the trench than its expected location.

Another important factor in determining the wave characteristics is scattering. Between the source region and the Jason-1 transect, the only bathymetric feature is the Ninety East Ridge (Fig. 5b); there are no isolated seamounts in this path. MofJeld et al. (2001) quantify the strength of scatterers in the Pacific using

$$
S=1-\frac{2 \epsilon}{1+\epsilon^{2}}
$$

where $\epsilon=\sqrt{H_{1} / H_{0}}, H_{1}$ is the feature depth and $H_{0}$ is the background depth. For the Ninety East Ridge, $H_{1} \sim 2.4 \mathrm{~km}$ and $H_{0} \sim 4.8 \mathrm{~km}$, so the strength of the scatterer is $S \sim 0.06$, which is very weak. The amplitude of the transmitted wave over the ridge will be close to the incident wave amplitude, so scattering, via wave reflections, does not play a significant role in the waveform evolution in this case.

\section{Significance of Ray Path Terminations}

In Sect. 3.2, we discussed how the back-projection of the tsunami waveform showed that the two satellites are sensitive to different portions of the margin. This difference is seen by the convergence of ray paths in Fig. 2 and by the clustering of Ray Path Terminations (RPTs) in Fig. 4. The convergence/ clustering indicates likely areas from which sea surface disturbances propagated, and the location of the RPTs can tell us about the rupture process.

We consider three observation points from each satellite. The first points, $1 \mathrm{j}$ and $1 \mathrm{t}$, denote the initial uplift location (selected at 10\% of the height of the lead wave) of Jason-1 and TOPEX, respectively. The third points, $3 \mathrm{j}$ and $3 \mathrm{t}$, denote the final down-drop below mean SSH. The second points, $2 \mathrm{j}$ and $2 \mathrm{t}$, are middle points, which for Jason-1 is the trough between the two peaks, and for TOPEX is an analogous point. We are able to apply the back-projection technique to these points, and not just the peaks of the lead wave (which travel at the group velocity), because the wavelengths of the lead wave are effectively non-dispersive (Fig. 3).

The RPTs for these points, shown in Fig. 4, illustrate the northeastern limit of the part of the margin that is capable of sending information to the satellite transect locations. Areas to the northeast of the RPTs are too far from the lead wave to reach the observation location in the specified time. Only areas to the southwest of the RPTs influence the lead wave morphology. Additionally, the RPTs located far from the margin are not significant, as nothing occurred in these areas that would have resulted in a tsunami. To the first order, the RPT locations for points $1 \mathrm{j}$ and $1 \mathrm{t}$ demarcate the updip limit of rupture, those for points $3 \mathrm{j}$ and $3 \mathrm{t}$ delimit the northeastern extent of uplift, and those for point $2 \mathrm{j}$ approximate a splay fault location.

While the features that we back-project are long wavelength and essentially non-dispersive, dispersion did modify the propagating waveform to separate the 
long and short wavelength components. Complexities arise due to the SWWS assumption and Figs. 7 and 9 show that the arrival time of the lead wave is only approximated by neglecting dispersion. Therefore, some care must be taken in attributing significance to the location of these RPTs and our rationale is outlined in the following sections.

\subsection{Initial Uplift (Points $1 j$ and 1t)}

The RPTs of the initial lead wave uplift of both satellites, points $1 \mathrm{j}$ and $1 \mathrm{t}$, are located very near to, but in the case of TOPEX, often do not approach, the deformation front. They show that the wavefront originated from off the coast of northern Sumatra, which is consistent with other back-projections of the tsunami wavefront (Fine et al., 2005; KuliKov, 2005; Hanson et al., 2007; Seno and Hirata, 2007). These points roughly correlate with the western extent of seafloor uplift, but their exact interpretation requires a discussion of two processes that work in opposition to one another. These are the effects of dispersive wave travel and the uncertainty in the time of seafloor uplift.

The results in Sect. 4.3.1 show that the SWWS is not truly an upper bound to the velocity of signal transport. Figure 7 shows that after $2 \mathrm{~h}$ of dispersive propagation, substantial uplift can travel on the order of $22 \mathrm{~km}$ ahead of the non-dispersive wave front that travels at the SWWS. We note, however, that the bulk of the uplift signal travels at the group velocity, which is slower than the SWWS. Figure 9, which compares dispersive and non-dispersive travel for the initial uplift pattern of interest, shows that the dispersive sea surface uplift can travel $12 \mathrm{~km}$ ahead of the nondispersive propagation (this was determined using the criterion that initial uplift occurs where the wave is $10 \%$ of the height of the initial disturbance). Therefore, by selecting the initial sea surface uplift, which can travel ahead of propagation at the SWWS, the RPTs underestimate the initial sea surface uplift location (see Fig. 11a). We define an underestimate as predicting an uplift location further seaward than the actual uplift location. Given this effect, these RPTs actually predict an initial sea surface uplift 12-22 km landward of their plotted locations.

The second effect is due to the difference between the time of earthquake initiation, $t=0$, and the time of seafloor uplift, $t=t_{s}$. Finite rise times, updip rupture velocities, and along strike rupture propagation imply that $t_{s}>0$, and the correct back-projection would be for a time $t_{m}-t_{s}$, where $t_{m}$ is the time of the satellite measurement. Unfortunately, we do not know $t_{s}$, and it varies along the margin, so we back-project to the hypocenter time. This allows for a propagation time $t_{m}$, which is too long and contributes to an overestimate of the initial uplift location (Fig. 11b). This suggests that the true western limit of seafloor uplift should be seaward of the RPTs.

If these two processes approximately equal each other, they cancel out and the RPTs of $1 \mathrm{j}$ and $1 \mathrm{t}$ represent the southwestern limit of initial seafloor uplift. This would imply a fault expression, very near to the trench. If the dispersive underestimate is a larger correction than the time effect overestimate, then the dispersive effect dominates and the initial uplift must have been landward of the RPTs. If the dispersive underestimate is a smaller correction than the time effect overestimate, then the time effect dominates, and the initial uplift must have reached further seaward than the RPT locations near the trench, a physically unlikely scenario.

\subsubsection{Constraint on Updip Rupture Propagation Speed}

The magnitude of $t_{s}$ can be approximated through a guess at the rise time and rupture velocity. Rupture velocities are generally $0.7-0.9$ of the shear wave speed (Aмmon et al., 2005), so we assume a $2.0 \mathrm{~km} / \mathrm{s}$ updip rupture velocity from an epicenter $200 \mathrm{~km}$ downdip (100 s correction). This updip velocity is notably smaller than the well constrained $2.8 \mathrm{~km} / \mathrm{s}$ average velocity parallel to the margin (IsHil et al., 2005). Heaton (1990) found that rise times are short compared to the overall duration of rupture and range from $0.3-5.0 \mathrm{~s}$ for earthquakes ranging in magnitude from $\mathrm{Mw}$ 5.9-8.1, with the longest rise time corresponding to the largest earthquake. Ammon et al. (2005) utilize $40 \mathrm{~s}$ rise times to capture the seismic energy released during the Sumatra-Andaman event, and similarly (Kiser and Ishii, personal communication) find that all of the energy has been released by a given point after $60 \mathrm{~s}$. 
(a)

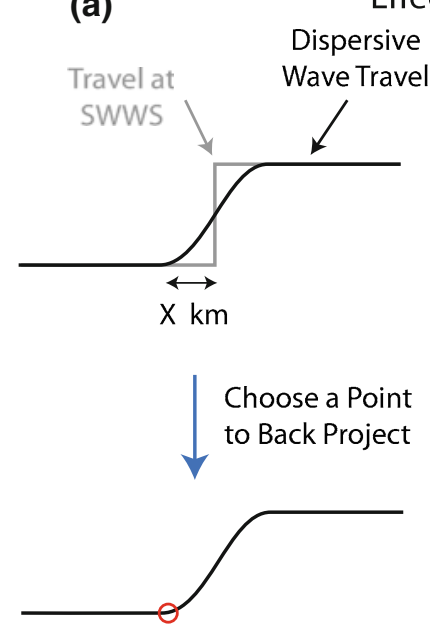

Effect of Dispersive Wave Travel
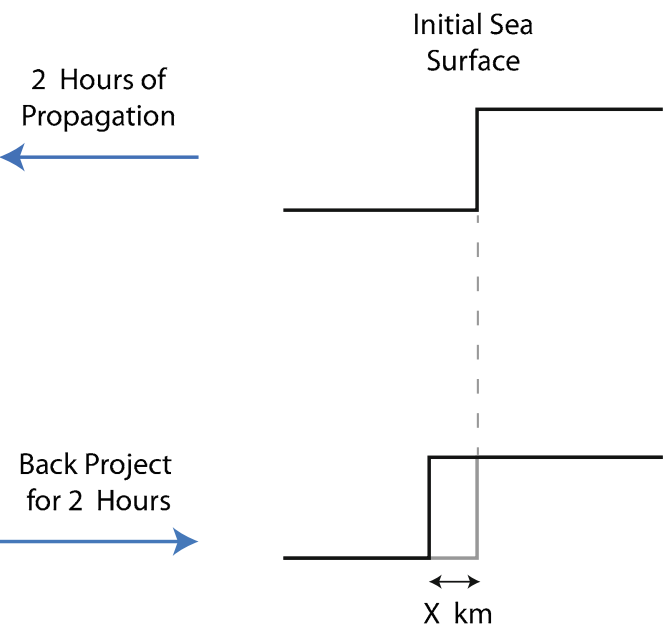

Underestimate of Initial

Sea Surface Uplift Location

(b)

\section{Effect of Back Projection Travel Time and Uncertain Rupture Velocities and Rise Times}

Earthquake at time $\mathrm{t}=0$
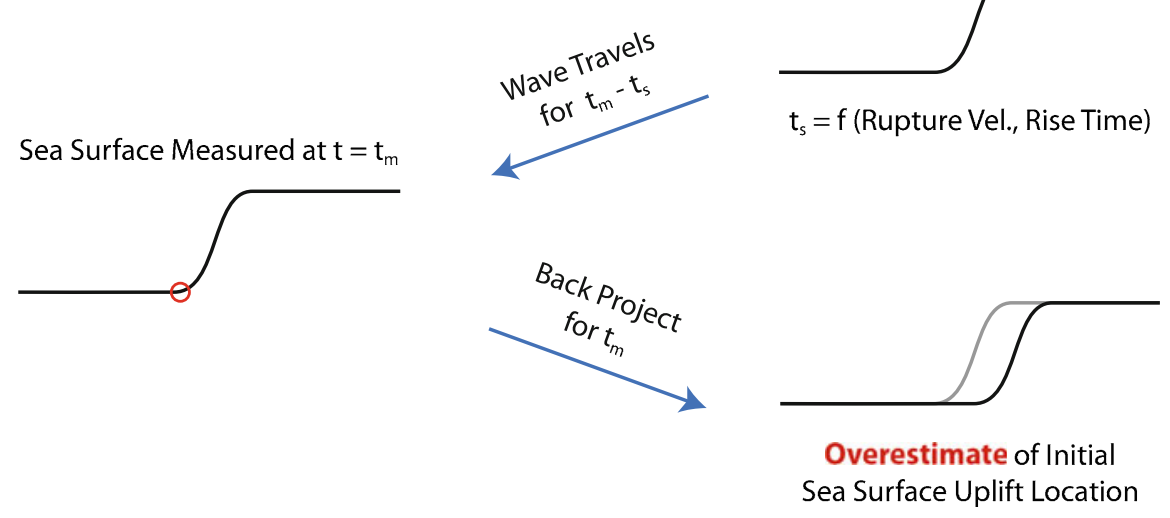

Sea Surface Uplift Occurs at $\mathrm{t}=\mathrm{t}_{\mathrm{s}}$

Figure 11

a Differences in wave propagation for dispersive and non-dispersive travel at the shallow water wave speed (SWWS) can lead to an underestimation of the initial sea surface uplift location. b Uncertainties in the rupture velocity and segment rise times can lead to an overestimation of the initial fault location

We quantify the effect of these times by simulating the updip propagation of rupture with a finite rise time using the $2 \mathrm{D}$ hydrodynamic model. The fault was divided into $5 \mathrm{~km}$ segments that slip at different times to represent a given velocity of updip rupture propagation, and a $60 \mathrm{~s}$ rise time was used. Figure 12 shows the effect on the waveform, after $2 \mathrm{~h}$ of propagation, for a range in rupture velocities with the same amount of slip on segments 1 and 3. The corrective term for the $2.0 \mathrm{~km} / \mathrm{s}$ rupture velocity and $60 \mathrm{~s}$ rise time is $21 \mathrm{~km}$, using the $10 \%$ of initial uplift criterion. This could also be approximated by using the time for rupture propagation, $100 \mathrm{~s}$, and calculating an offset for travel at the SWWS of $200 \mathrm{~m} / \mathrm{s}$. 

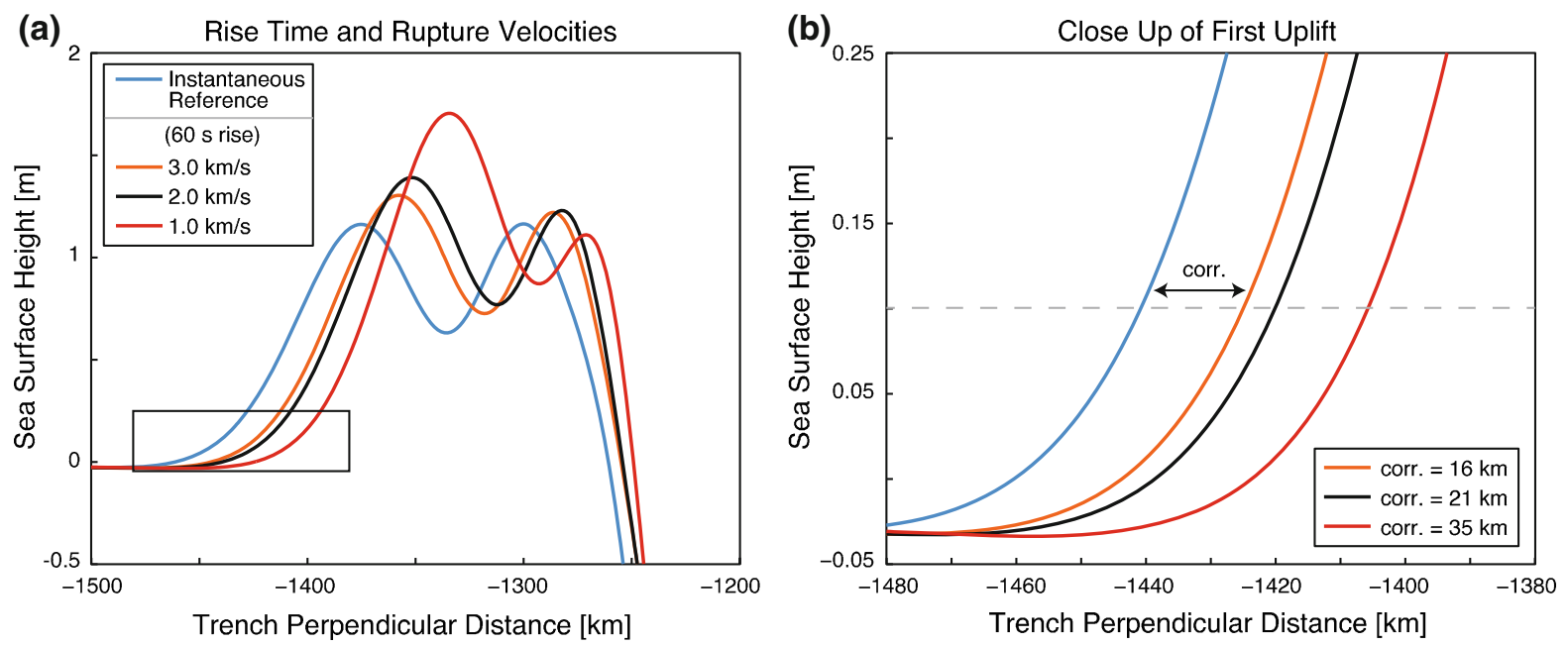

Figure 12

a Lead wave variation as an updip rupture velocity and rise times are included. Reference case has no rise time and infinite updip rupture velocity. Other three lines include a $60 \mathrm{~s}$ rise time but varying updip rupture propagation speeds (b) Close up of the front of the lead wave and a measure of the offset from the ideal reference case assumed by the back-projection

This results in a $20 \mathrm{~km}$ offset and agrees with the exact 2D model results shown in Fig. 12.

Fast updip rupture propagation times, $\geq 2.0 \mathrm{~km} / \mathrm{s}$, result in $16-21 \mathrm{~km}$ corrections, which balance the dispersive correction. In the case of Jason-1, this would indicate that rupture reached the trench. If the rupture travels more slowly, $1.0 \mathrm{~km} / \mathrm{s}$, the corrective term is $34.8 \mathrm{~km}$, and in this case, the time-corrective term is greater than the dispersive correction, and uplift must reach seaward of the trench. Since this is unlikely, a fast rupture propagation is required to explain the Jason-1 data.

The observation remains that the TOPEX and Jason-1 RPTs do not overlay one another, and the TOPEX RPTs do not reach the trench. Even with the fastest rupture velocities, the RPTs indicate that uplift reached just seaward of the trench. This is not likely, so there may be some other consideration that we have not accounted for here that explains this difference.

\subsection{Double Peak Separation and Final Down Drop (Points 2j, 3j and 3t)}

The wavelength of the features that we backproject are essentially non-dispersive (Fig. 3), which is why we are able to back-project points that are not peaks. But dispersion has acted on the waveform to modify it from its original morphology and Fig. 3 shows that the wavelength of the initial uplift due to slip on a splay fault is significantly affected by dispersion. Therefore, we do not attribute a precise meaning to the location of these RPTs, but some information can be attained from their locations.

The RPTs of the end of the lead waveforms, or where the sea surface depression begins (points $3 \mathrm{j}$ and $3 \mathrm{t}$, red dots), align with one another and correlate with the eastward limit of original seafloor uplift. Point $2 \mathrm{j}$ is the trough between the peaks and its RPTs (purple dots) are related to the potential location of a splay fault. The distance between the RPTs of $2 \mathrm{j}$ and the deformation front depends on the location along strike, but ranges from $70-120 \mathrm{~km}$. The area of uplift due to a splay fault, if one exists, will be roughly bracketed by the RPTs of points $2 \mathrm{j}$ and $3 \mathrm{j}$. The area bracketed by these RPTs is a bathymetric high. Therefore, splay fault uplift, just offshore of Simeulue, may be consistent with producing the second peak of the Jason-1 observations.

\section{Supporting Evidence for Splay Faulting from Geodetic and Seismicity Observations}

\subsection{Simeulue Observations of Uplifted Corals}

The splay fault that we propose from the backprojection results is very close to Simeulue Island and 
correlates with a bathymetric high to the northwest of Simeulue. If this continues further to the north, this structure could correlate with the "upper splay fault (USF)" observed from OBS deployments and believed to have slipped during the earthquake (SiBuet et al., 2007; Lin et al., 2009). We examine the uplift of corals, reported by MeLtzNER et al. (2006), to see if there is additional support for splay fault activation near Simeulue. Meltzner et al. (2006) found regions of significant uplift $(145 \mathrm{~cm})$ on the western tip of the island, very close to areas of only modest uplift $(40 \mathrm{~cm})$ on the northern tip of the island (Fig. 13c). This large difference in uplift occurs over only $22.5 \mathrm{~km}$. These measurements were

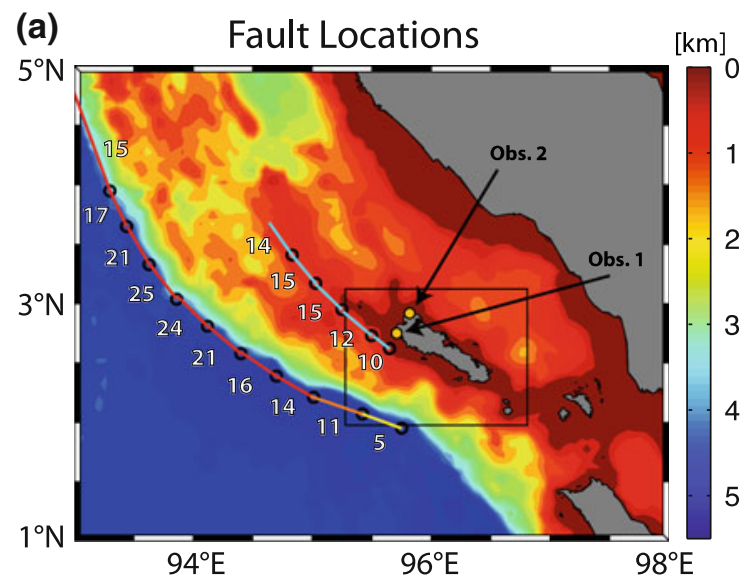

(e)

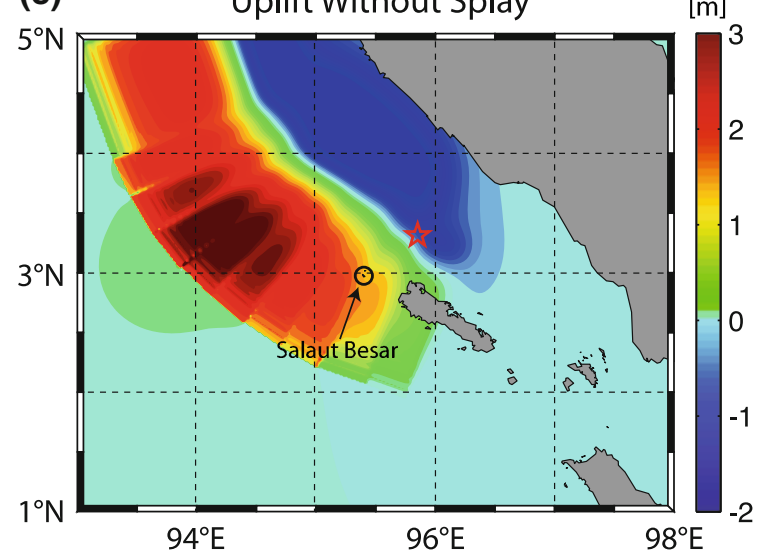

made in mid-January of 2005, and therefore were not influenced by the 2005 Nias event, but due to the delay it cannot be certain that all of this deformation is coseismic. We seek to determine if this large gradient could be the result of a splay fault.

We consider a detailed fault model in the area of Simeulue island and determine seafloor deformation using the Okada method (OKADA, 1985) to evaluate the uplift at precise locations on Simeulue (Fig. 13a). We subdivide the subduction interface into $\sim 35 \mathrm{~km}$ along-strike segments with an $8^{\circ}$ dip. These extend $210 \mathrm{~km}$ downdip and are divided into 36 downdip segments, each of which can be prescribed a different amount of slip. The width of the fault changes with (b)

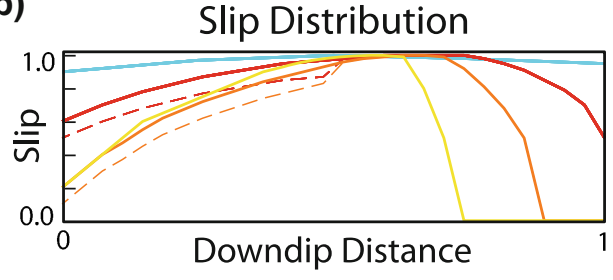

(c)

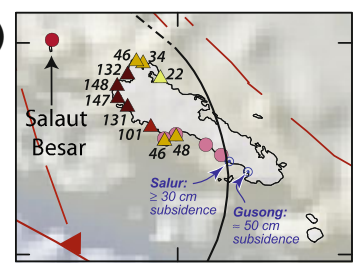

(d)

\begin{tabular}{|l|cc|}
\hline & Obs. 1 & Obs. 2 \\
\hline Real Uplift & $145 \mathrm{~cm}$ & $40 \mathrm{~cm}$ \\
\hline With Splay & $131 \mathrm{~cm}$ & $49 \mathrm{~cm}$ \\
Without Splay & $81 \mathrm{~cm}$ & $56 \mathrm{~cm}$ \\
\hline
\end{tabular}

(f)

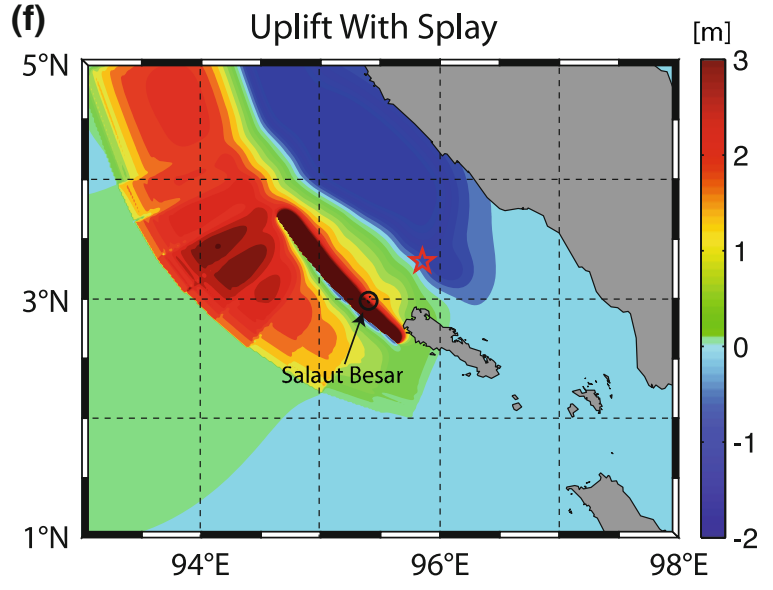

Figure 13

a Fault locations with peak slip amounts and observation locations. b All fault segments have a downdip slip distribution like shown here, color coded to the fault segment in a. Slip distribution is normalized by the peak slip amount and the downdip distance. c From MeltzNER et al. (2006) showing the large gradient in uplift on the north side of Simeulue island. Colored points are locations of measurements of uplifted corals and numbers denote the $\mathrm{cm}$ of uplift. $\mathbf{d}$ Table of observed and modeled uplifts. e Seafloor uplift for a model without a splay fault. f Seafloor uplift for a model that includes a splay fault 
depth so that there is no overlap, in map view, of the fault segments. Splay faults are located approximately $100 \mathrm{~km}$ landward (depending on the location), and are meant to trace the front of the bathymetric high. The location of this splay fault agrees with the back-projection, which shows that the area of the margin uplift that could lead to the second peak is bracketed by the RPTs of $2 \mathrm{j}$, and $26 \mathrm{~km}$ seaward of the RPTs of $3 \mathrm{j}$. The splay segments dip at $50^{\circ}$, with a downdip length of $18 \mathrm{~km}$, and are divided into five downdip segments.

Figure 13a shows the surface expression of fault segments used to determine uplift at Simeulue Island, although only the southernmost faults affect the uplift at observation points 1 and 2 . These faults do not slip uniformly but rather have a downdip slip distribution shown in Fig. 13b, which are color coded to the segment color in 13a and normalized by the maximum slip and the downdip dimension. We use a down dip slip distribution of this form guided by slip distributions from the rate-and-state modeling of earthquake sequences (e.g., LiU and RicE, 2007). The numbers by the fault segments denote the maximum amount of slip on that segment and were chosen based on the slip distribution of CHLIEH et al. (2007), which does not use large patches of uniform slip but rather a smoothly varying profile. If splay faults are active in the area, less slip is prescribed on the updip portion of the subduction interface, as implemented in the hydrodynamic models (dashed lines in Fig. 13b).

The seafloor uplift due to a model with splay fault slip and one without a splay fault are shown, with all slip amounts on the subduction interface the same except for the updip decrease in slip if there is a splay fault. The uplift at two observation points is reported in Fig. 13d and the case with a splay fault more closely matches observations. It is difficult to obtain such a gradient of slip with smooth slip distributions on the subduction interface. With the presence of a steeply dipping splay fault off the coast of Simeulue, large local uplifts are possible on the western tip while preserving only modest uplifts on the northern tip.

Of course it is possible to create a slip distribution on just the main interface that would result in the observed uplifts, but it would require a localized region of high slip, $(\sim 35 \mathrm{~km}$ downdip extent $)$ directly up and down dip of which there is little to no slip. This could create localized uplift in the same area as where we place a splay fault. Through the utilization of down dip slip profiles that are smooth, like that of CHLIEH et al. (2007), and only having slip on the subduction interface, it is not possible to produce the observed uplift gradient (Fig. 13d, e). Therefore, slip on a splay fault is consistent with the observations of uplifted corals, but we cannot rule out other causes of the uplift gradient.

\subsection{Surface Deformation on Salaut Besar Island}

The island of Salaut Besar is located approximately $40 \mathrm{~km}$ northwest of Simeulue Island and its location is denoted in Figs. 13 and 15. This island is in the area that we have identified as a potential splay fault location (Fig. 13). In February of 2009 a survey of the island revealed a fresh scarp with nearly $2 \mathrm{~m}$ of relief at the southern end on this island (MELTZNER et al., 2010). The strike of the scarp was to the northwest, roughly parallel to the trench, although the scarp could not be mapped for its entire along strike extent due to the dense jungle. Field evidence suggests that this scarp is of tectonic origin rather than the result of reef collapse. While observations of this structure were not made until approximately 4 years after the 2004 event, field evidence leads to the interpretation that this deformation occurred during the 2004 event rather than as a result of a smaller aftershock in the area (MELTZNER et al., 2010).

The location of the splay fault in Fig. 13 was based on seafloor bathymetry, and Salaut Besar is not located near the surface expression of the proposed splay fault. The sense of slip on this structure is down to the east and if this was the surface expression of the splay fault we would expect that the sense of slip would be up to the east. Therefore, we interpret this scarp as an expression of the deformation that occurs to accommodate the motion of material through a fault bend, similar to the type of deformation seen in fault-bend-fold theory (Suppe, 1983). We show a schematic representation of the type of deformation in Fig. 14 as a combination of the elastic and kinematic end members, both of which describe the deformation but result in very different surface uplift 


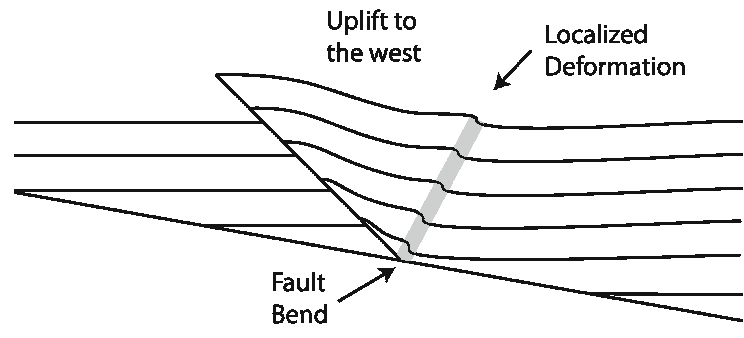

Figure 14

Schematic representation of the localized deformation that can occur as material moves through a fault bend. The scarp on Salaut Besar may be due to this type of deformation

patterns. Surface uplift resulting from this localized deformation would have the observed sense of slip with uplift to the west. Structures with this orientation and sense of motion have been observed in seismic reflection images (e.g., CoRREDOR et al., 2005).

While the vergence of this fault is not the same as would be expected for the splay fault considered in Fig. 6a, the observation of surface deformation in this area is strong evidence in support of the notion that there was localized coseismic deformation in the area of the proposed splay fault during the 2004 earthquake. KLINGELHOEFER et al. (2010) observed many landward and seaward vergent faults in the accretionary prism to the northwest of Salaut Besar. One of these landward vergent structures roughly correlates with the observed surface deformation and may indicate the presence of a family of such faults in the area (Meltzner et al., 2010).

\subsection{Observations of Aftershock Seismicity}

The final issue that we address is the aftershock seismicity following the earthquake. Figure 15a shows relocated aftershocks in the time between the 2004 Sumatra-Andaman earthquake and the 2005 Nias earthquake to the south (ENGDAHL et al., 2007; PesiceK et al., 2010). The two significant features are the cluster of seismicity to the northwest of Simeulue, and the gap in seismicity updip and to the west of that cluster, both of which persisted after the Nias earthquake. Figure $15 \mathrm{~b}$ shows the global CMT solutions for the same time period plotted at the updated relocations.

Many of the events in the cluster of seismicity have nodal planes consistent with slip on the subduction interface. Several studies have concluded that this is a cluster of interplate events (DEwEY et al., 2007; Tilmann et al., 2010) not consistent with slip on a splay. TiLmann et al. (2010) examine a (a)

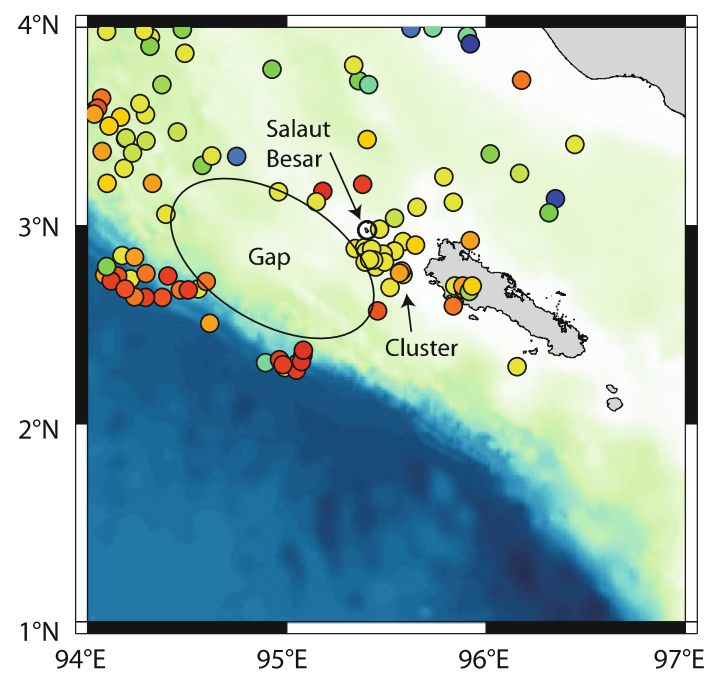

(b) Reclocated CMT Solutions

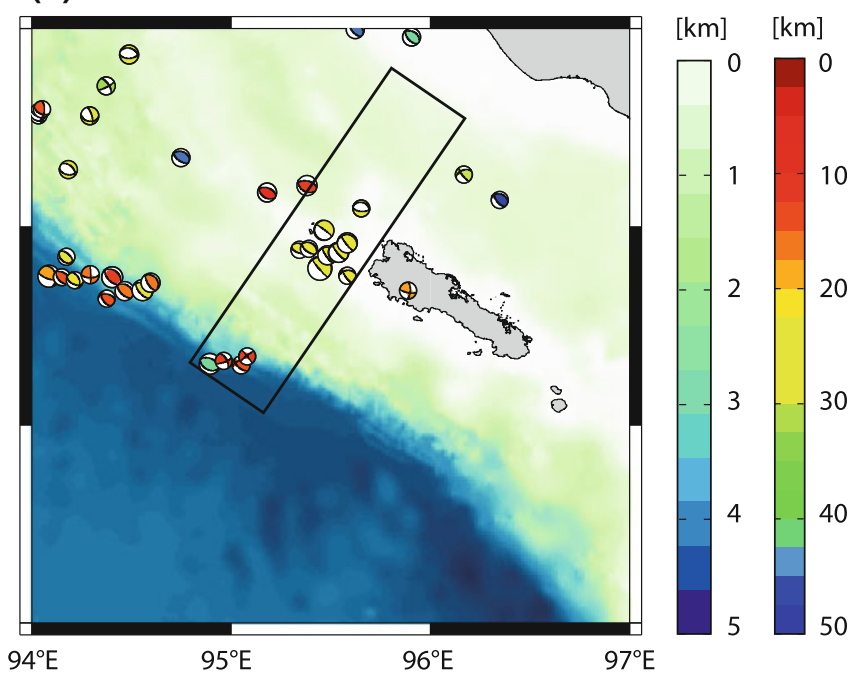

Figure 15

Seismicity between the December 26, 2004 Sumatra-Andaman earthquake and the March 28, 2005 Nias earthquake. a Relocated seismicity from Pesicek et al. (2010). b Events in the CMT catalog at the relocated points from the PesiceK et al. (2010) catalog. Black box shows the section of seismicity that is reproduced in Fig. 16 
southeastward extension of this cluster into the Nias event area, and conclude that this cluster demarcates the updip limit of slip at the seismic/aseismic transition. They argue that there are no aftershocks updip of this band since it is the aseismic region.

We propose an alternative explanation for the cluster and the updip gap in seismicity based on Coulomb failure stress (CFS) changes due to slip on the faults (KING et al., 1994). Increases in CFS account for both increases in shear and decreases in compression that bring a fault closer to failure. A change in CFS is defined as

$$
\Delta \mathrm{CFS}=\Delta \tau-\mu \Delta \sigma_{n}
$$

where $\mu$ is the coefficient of friction (here $\mu=0.6$ ), and $\tau$ and $\sigma_{n}$ are the shear and normal stresses (positive in compression) resolved on a plane, respectively. The stress changes are calculated using the method developed by Okada (OKADA, 1985). Aftershocks would be more likely in areas of increased CFS, so the fault slip distribution should lead to an increase in CFS in the region of the aftershock cluster and a decrease in CFS where the seismicity gap is observed.

Figure 16 shows the change in CFS on the subduction interface using an $8^{\circ}$ main fault dip, $45^{\circ}$ splay fault dip and four slip scenarios. Since the stresses are determined from a dislocation solution, there is a large stress concentration at the termination of a dislocation. We plot the signed $\log _{10}(|\Delta \mathrm{CFS}|)$ so that the dislocation does not dominate the solution and the difference between increases and decreases in CFS are preserved.

TiLmann et al. (2010) propose that the gap in seismicity is due to the termination of slip at depth (case 1 in Fig. 16), but the $\Delta$ CFS solution shows that

(a)

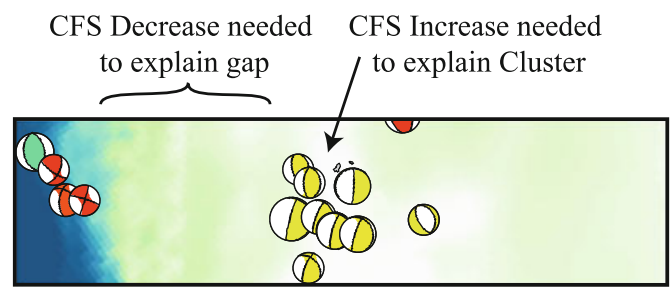

(b)

Change in Coulomb Failure Stress

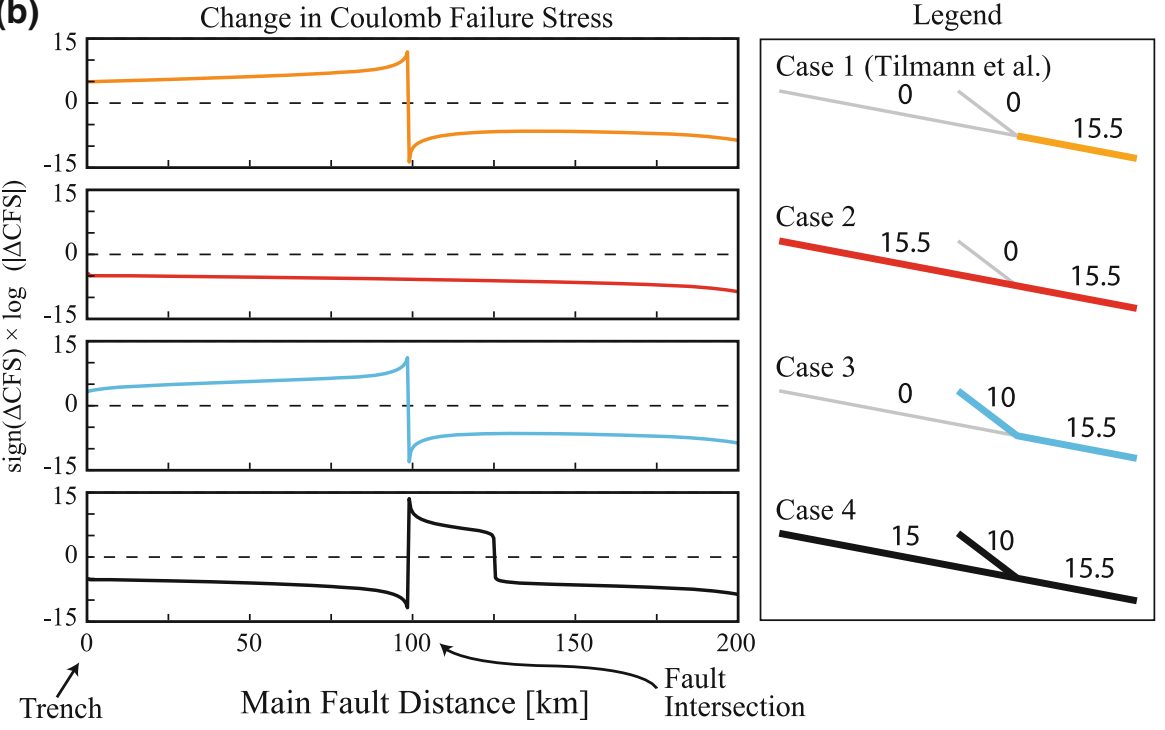

Figure 16

a To explain the seismicity observations, a decrease in CFS is needed on the updip segment, and an increase is needed half way down. b Change in Coulomb failure stress (CFS) on the subduction interface for four scenarios of slip distribution (note the nonlinear scale). Numbers in legend indicate the amount of slip on each of the three segments. Case 4 has the same slip amounts as the "equal peak" case shown in Fig. 8 and can explain the seismicity cluster an the gap. The case of slip on both faults is the only explanation for this 
this slip distribution leads to an increase in CFS on the updip extension of the subduction interface. This should result in an increase in seismicity, which would not agree with the observation of a seismicity gap. Case 4, which we advocate here, has slip on both the subduction interface and a splay fault. The interactions at the fault junction result in a CFS increase just downdip of the intersection, and a decrease in CFS updip on the subduction interface. This scenario can explain both the seismicity cluster, with a localized area of increased CFS, and the gap in seismicity, with a decrease in CFS updip on the interface. For completeness, we examine two other slip distributions. Case 2 involves slip on the entire subduction interface, which decreases the CFS on the interface, explaining the seismicity gap, but there is no increase in CFS to explain the cluster of seismicity. Case 3 has slip transitioning to a splay fault at depth, but this does not significantly differ from case 1 , and would also not explain the gap in seismicity.

Therefore, of the four models considered here, slip on both the subduction interface and a splay is the only slip distribution that can explain the observed pattern of aftershock seismicity. However, there are other factors that affect the Coulomb stress distribution, such as non-planar fault geometries and gradients in slip. Since we do not consider all factors here, there may be another explanation for the cluster and gap in seismicity, but the co-activation of a splay and the subduction interface is consistent with observations.

\section{Conclusions}

We find that there is evidence that supports the coseismic activation of a splay fault off the coast of northern Sumatra, but we cannot conclusively determine if a splay fault ruptured. This support comes from satellite observations of the propagating tsunami, as well as local coral uplift data, observations of surface deformation in the proposed splay fault location, and patterns in aftershock seismicity.

We examine sea surface altimetry measurements of two satellites that traversed the Indian ocean $2 \mathrm{~h}$ after the Sumatra-Andaman earthquake. These satellites recorded remarkably different signals given their proximity in space and time. The Jason-1 satellite recorded a doubly-peaked lead wave, while the TOPEX satellite did not.

To understand the cause of this disparity, we back-project the lead wave of the tsunami waveform observed by both of these satellites. We find that the difference between the two satellite signals is a path effect due to the refraction of long wavelength waves interacting with the bathymetry of the open ocean. The complex ray path propagation over the Ninety East Ridge is responsible for convergence patterns that lead to a sampling difference. The Jason-1 satellite is sensitive to the epicentral region, where geodetic and seismic evidence support the possibility that a splay fault was activated, while TOPEX is sensitive to a region to the north of this, where there is no evidence for splay fault rupture.

The coseismic activation of both a splay fault and the subduction interface results in two areas of seafloor uplift. Our 2D and 3D models of wave propagation show that this uplift signature should be preserved and recognizable after $2 \mathrm{~h}$ of propagation across the open ocean. We find that it is only with dispersion that the details of the waveform can be properly modeled and the morphology of the wave can evolve as it propagates. Dispersive wave travel also results in uplift traveling ahead of what would be suggested by the shallow water wave speed, which is commonly thought to be an upper bound to the travel of sea surface disturbances. With dispersion the sea surface uplift due to co-activation of both the subduction interface and a splay evolves into a morphology like the two peaks of the Jason-1 signal.

Some models are able to produce the double peak observed by Jason-1, but we note that the existence of scenarios in which there is no need for slip on a splay fault does not preclude the possibility of splay fault rupture. Some of these models require a rupture duration that is twice as long (FuJII and SATAKE, 2007; GRILLI et al., 2007) as the $500 \mathrm{~s}$ observed from seismic records (AMMON et al., 2005; IsHII et al., 2005). Other models require a "checkerboard" slip distribution, with isolated areas of high slip and low-to-no slip in the regions between (HIRATA et al., 2006; LoRito et al., 2010). By using a small number of large subfaults with this slip pattern, isolated seafloor uplifts occur that can result in a double peak. This will not necessarily reflect some of the more gradual changes in slip distribution 
that can occur and does not agree with some seismic and geodetic slip inversions for this event. Smoother spatial slip distributions would remove this artifact, and may result in an increased ability to recognize the signature from slip on a splay fault.

A close analysis of the back-projection of the waveform leads us to conclude that the rupture must have reached very near to the trench very soon after the start of the event. A fast updip rupture velocity, of order $2.0 \mathrm{~km} / \mathrm{s}$ or more, is required to achieve this. From the back-projection, we are able to isolate the part of the margin where splay fault uplift could have occurred to create the second peak observed by Jason-1. This region correlates with where localized uplift must occur to explain the large gradient in coral uplift patterns of MelTzNer et al. (2006) and with where a fault scarp was observed indicating significant coseismic deformation in this area (MelTzNER et al., 2010).

Additional support for splay fault rupture includes an aftershock seismicity cluster northwest of Simeulue and a gap in aftershock seismicity updip of this cluster. We find that the $\triangle \mathrm{CFS}$ distribution due to slip on both a splay fault and the subduction interface can explain both of these seismicity features. The stress distribution has a stress increase concentration at the downdip end of the splay (resulting in the seismicity cluster) and a stress shadow on the subduction interface (resulting in a seismicity gap).

\section{Acknowledgments}

This research was supported by the National Science Foundation EAR award 0809610. We thank Renata Dmowska for bringing evidence of possible splay faulting in the 2004 Sumatra-Andaman earthquake to our attention, Philip Liu for a 2007 conference lecture that made it clear that tsunami response to discontinuous uplift of the seafloor was not yet well treated and also for making publicly available his COMCOT program for Boussinesq modeling, Yajing Liu for initial guidance on use of the Okada program, Brendan Meade for an Okada implementation in Matlab, Eric Geist, Stephan Grilli, Emile Okal, George Papanicolaou and Costas Synolakis for various discussions on tsunami modeling, and Aaron Meltzner and Kerry Sieh for noting their observations of surface rupture. We would also like to thank two anonymous reviewers for their suggestions to improve the clarity of this manuscript.

Open Access This article is distributed under the terms of the Creative Commons Attribution Noncommercial License which permits any noncommercial use, distribution, and reproduction in any medium, provided the original author(s) and source are credited.

\section{Appendix: Potential Flow Solution}

As is well known (e.g., Lamb, 1932; MiLneThomson, 1968; Batchelor, 1967), the Euler equations of motion for a uniform inviscid and incompressible fluid initially at rest can be solved for velocity $\vec{u}$ and pressure $p$ in terms of a velocity potential $\phi=\phi(x, y, z, t)$ by

$$
\vec{u}=\nabla \phi \quad \text { and } \quad p=-\rho g z-\rho \frac{\partial \phi}{\partial t}-\frac{1}{2} \rho|\nabla \phi|^{2}
$$

where $\rho$ is density, and $z$ is the vertical coordinate, with positive up. Substitution into the continuity equation results in the Laplace equation

$$
\nabla^{2} \phi=0
$$

Linearized boundary conditions on the sea surface, $z=0$, and the seafloor, $z=-H$, are

$$
\frac{\partial \phi}{\partial z}=\frac{\partial \zeta}{\partial t} \quad \text { at } \quad z=-H
$$

$$
\frac{\partial \phi}{\partial z}=\frac{\partial \eta}{\partial t} \quad \text { and } \quad \frac{\partial \phi}{\partial t}=-g \eta \quad \text { at } \quad z=0
$$

where $\eta(x, y, t)$ is the uplift of the sea surface from $z=0$ and $\zeta(x, y, t)$ is the uplift of the seafloor, vanishing for $t<0$. The boundary condition at the seafloor represents the coupling of the seafloor normal velocity to the fluid velocity, while the boundary conditions at the sea surface include the kinematic condition that a particle does not leave the sea surface, as well as $p=0$ on the sea surface.

In the $2 \mathrm{D}$ case, we represent the solution in the form

$$
\left\{\begin{array}{c}
\phi(x, z, t) \\
\eta(x, t)
\end{array}\right\}=\frac{1}{2 \pi} \int_{-\infty}^{\infty}\left\{\begin{array}{c}
\tilde{\phi}(k, z, t) \\
\tilde{\eta}(k, t)
\end{array}\right\} \mathrm{e}^{i k x} \mathrm{~d} k
$$

similarly to KaJiura (1963), Mei (1989) and DutYKh et al. (2006), where $\tilde{\phi}$ and $\tilde{\eta}$ are Fourier transforms in 
$x$, and find that for a sudden uplift of the seafloor, $\zeta(x, t)=\zeta_{0}(x) U(t)$, where $U(t)$ is the unit step function and $\zeta_{0}(x)$ is the final seafloor uplift. This becomes the KAJIURA (1963) solution

$$
\eta(x, t)=\frac{1}{2 \pi} \int_{-\infty}^{\infty} \frac{\tilde{\zeta}_{0}(k) \mathrm{e}^{i k x} f(k, t)}{\cosh (k H)} \mathrm{d} k
$$

where

$$
\begin{gathered}
f(k, t)=\cos [k c(k) t]=\frac{1}{2} \mathrm{e}^{i k c(k) t}+\frac{1}{2} \mathrm{e}^{-i k c(k) t} \\
c(k)=\sqrt{\frac{g}{k} \tanh (k H)}
\end{gathered}
$$

For uplifts with a finite rise time duration, $T, \zeta(x, t)=$ $\zeta_{0}(x) R(t)$, where $R(t)$ is a ramp function with $R(t)=t / T$ for $0<t \leq T$ and $R(t)=1$ for $t>T$, we have the solution

$$
\eta(x, t)=\frac{1}{2 \pi} \int_{-\infty}^{\infty} \frac{\tilde{\zeta}_{0}(k) \mathrm{e}^{i k x}(g(k, t-T)-g(k, t))}{i k c(k) \cosh (k H)} \mathrm{d} k
$$

where

$$
g(k, t)=\frac{1}{2} \mathrm{e}^{-i k c(k) t}-\frac{1}{2} \mathrm{e}^{i k c(k) t}
$$

This leads to our numerical modeling procedure, treating $\tilde{\zeta}_{0}(k)$ as a set of $M$ (an even integer) equally spaced Delta functions of complex strength $A_{m}$, or $A_{ \pm M / 2} / 2$ when $m= \pm M / 2$, located along the $k$ axis, so as to represent any sudden uplift distribution $\zeta_{0}(x)$ as the real, finite Fourier series

$$
\zeta_{0}(x)=\sum_{m=-M / 2}^{M / 2} \frac{A_{m} \mathrm{e}^{i k_{m} x}}{\Lambda_{M m}}=A_{0}+2 \operatorname{Re}\left[\sum_{m=1}^{M / 2} \frac{A_{m} \mathrm{e}^{i k_{m} x}}{\Lambda_{M m}}\right]
$$

Here

$$
\begin{gathered}
k_{m}=\frac{2 \pi m}{L} \quad \text { and } \quad A_{-m}=\bar{A}_{m} \\
\Lambda_{M m}=1+\delta_{\frac{M}{2}|m|}= \begin{cases}2, & \text { if }|m|=M / 2 \\
1, & \text { otherwise }\end{cases}
\end{gathered}
$$

where the over-bar means complex conjugate, and $L$ is the period of the Fourier series, always taken much larger than the domain to be modeled to avoid contributions, within the time considered, from the spatially periodic replications (of repeat length $L$ ) of the resulting sea surface disturbance.

The $A_{m}$ are determined by doing a Fast Fourier Transform (FFT) on the function $\zeta_{0}(x)$, now effectively redefined as being the above finite Fourier series, and hence a function that is periodic in $x$ with repeat a length $L$. The series is in turn defined in terms of the values of the given $\zeta_{0}(x)$ at $M$ equally spaced sample points over a length $L$. Thus if $\zeta_{0}\left(x_{p}\right)$, where $x_{p}=p L / M$ and $p=0,1,2, \ldots, M-1$, is specified and understood to be replicated periodically, the $A_{m}$ are given by

$$
A_{m}=\frac{1}{M} \sum_{p=0}^{M-1} \zeta_{0}\left(x_{p}\right) \mathrm{e}^{-i k_{m} x_{p}}
$$

and such factors $A_{m}$ can be recognized from a standard FFT output.

The solution for the sea surface uplift in response to that seafloor motion is then

$$
\eta(x, t)=\sum_{m=-M / 2}^{M / 2} \frac{A_{m} \mathrm{e}^{i k_{m} x} f\left(k_{m}, t\right)}{\Lambda_{M m} \cosh \left(k_{m} H\right)}
$$

So we simply evaluate that finite Fourier series for $\eta(x, t)$ in our numerical procedure, and when we consider locations that are far from the uplifted region of seafloor, it suffices to keep the single term of $f\left(k_{m}, t\right)$, which corresponds to wave propagation in the appropriate direction.

This 2D formulation is extended to $3 \mathrm{D}$ as explained in the main text.

\section{REFERENCES}

Ammon, C. J., et al. (2005), Rupture process of the 2004 SumatraAndaman earthquake, Science, 306, 1133-1139.

Araki, E., M. Shinohara, K. Obana, T. Yamada, Y. Kaneda, T. Kanazwa, and K. Suyehiro (2006), Aftershock distribution of the 26 December 2004 Sumatra-Andaman earthquake from ocean bottom seismographic observation, Earth Planets Space, 58, 113-119.

Baba, T., P. R. Cummins, T. Hori, and Y. Kaneda (2006), High precision slip distribution of the 1944 Tonankai earthquake inferred from tsunami waveforms: Possible slip on a splay fault, Tectonophysics, 426, 119-134.

Banerjee, P., F. Pollitz, B. Nagarajan, and R. Burgmann (2007), Coseismic slip distributions of the 26 December 2004 
Sumatra-Andaman and 28 March 2005 Nias earthquakes from GPS static offsets, Bull. Seism. Soc. Am., 97(1A), S86-S102.

Batchelor, G. (1967), An Introduction to Fluid Dynamics, Cambridge University Press.

ChLien, M., et al. (2007), Coseismic slip and afterslip of the great $M w=9.15$ Sumatra-Andaman earthquake of 2004, Bull. Seism. Soc. Am., 97(1A), S152-S173.

Corredor, F., J. H. SHAw, F. Bilotti (2005), Structural styles in the deep-water fold and thrust belts of the Niger Delta, Amer. Assoc. Pet. Geol., 89(6), 753-780, doi:10.1306/02170504074.

DeDontney, N., and J. R. Rice (2007), Role of splay faulting and dispersion in tsunami waveforms, EOS Trans. Amer. Geophys. Union, 88(52), Fall Meet. Suppl., Abstract S53A-1040.

DeDontney, N. L. (2011), Branch faulting in subduction and strike-slip settings, Ph.D. thesis, Harvard University

Dewey, J. W., G. Choy, B. Presgrave, S. Sipkin, A. C. Tarr, H. BENZ, P. EARLE, and D. WALD (2007), Seismicity associated with the Sumatra-Andaman island earthquake of 26 December 2004, Bull. Seis. Soc. Am., 97(1A), S25-S42, doi:10.1785/0120050626.

Dutykh, D., F. Dias, and Y. Kervella (2006), Linear theory of wave generation by a moving bottom, C. R. Acad. Sci. Paris, Ser. I(343), 499-504, doi:10.1016/j.crma.2006.09.016.

Engdahl, E. R., A. Villasenor, H. R. DeShon, and C. H. Thurber (2007), Teleseismic relocation and assessment of seismicity (1918-2005) in the region of the 2004 Mw 9.0 Sumatra-Andaman and 2005 Mw 8.6 Nias Island great earthquakes, Bull. Seis. Soc. Amer., 97(1A), S43-S61, doi:10.1785/0120050614

Fine, I. V., A. B. Rabinovich, and R. E. Thomson (2005), The dual source region for the 2004 Sumatra tsunami, Geophys. Res. Lett., 32, L16602, doi:10.1029/2005GL023521.

Fisher, D., D. Mosher, J. A. A. Jr, S. P. Gulick, T. Masterlard, and K. MoRan (2007), Active deformation across the Sumatran forearc over the December 2004 Mw 9.2 rupture, Geology, 35(2), 99-102, doi:10.1130/G22993A.1.

FujII, Y., and K. SATAKe (2007), Tsunami source of the 2004 Sumatra-Andaman earthquake inferred from tide gauge and satellite data, Bull. Seism. Soc. Am., 97(1A), S192-S207.

Geist, E. L., and R. Dмоwsкa (1999), Local tsunamis and distributed slip at the source, Pure Appl. Geophys., 154, 485-512.

Gower, J. (2007), The 26 December 2004 tsunami measured by satellite altimetry, Inter. J. Remote Sensing, 28(13-14), 2897-2913.

Grildi, S. T., M. Ioualalen, J. Asavanant, F. Shi, J. T. Kirby, and P. WATTS (2007), Source constraints and model simplations of the December 26, 2004, Indian ocean tsunami, J. Water., Port, Coast., Ocean Eng., 133(6), 414-428, doi:10.1060/(ASCE)0733950X(2007)133:6(414).

Guilbert, J., J. Vergoz, E. Schissele, A. Roueff, and Y. Cansi (2005), Use of hydroaboustic and seismic arrays to observe rupture propagation and source extent of the $M w=9.0$ Sumatra earthquake, Geophys. Res. Lett., 32, L153310, doi:10.1029/ 2005 GL022966.

Hanson, J. A., and J. R. Bowman (2005), Dispersive and reflected tsunami signals from the 2004 Indian Ocean tsunami observed on hydrophones and seismic stations, Geophys. Res. Lett. 32, L17606, doi:10.1029/2005GL023783.

Hanson, J. A., C. L. Reasoner, and J. R. Bowman (2007), Highfrequency tsunami signals of the great Indonesian earthquakes of 26 December 2004 and 28 March 2005, Bull. Seis. Soc. Am., 97(1A), S232-S248, doi:10.1785/0120050607.
Heaton, T. H. (1990), Evidence for and implications of self-healing pulses of slip in earthquake rupture, Phys. Earth Planet. Inter., 64, 1-20.

Henstock, T. J., L. C. McNeill, and D. R. Tappin (2006), Seafloor morphology of the Sumatran subduction zone: Surface rupture during megathrust earthquakes? Geology, 34(6), 485-488.

Hino, R., Y. TANioka, T. Kanazawa, S. Sakai, M. Nishino, and K. SuYeHIro (2001), Micro-tsunami from a local interplat earthquake detected by cabled offshore tsunami observation in northeastern Japan, Geophys. Res. Lett., 28(18), 3533-3536.

Hirata, K., K. Satake, Y. Tanioka, T. Kuragano, Y. Hasegwa, Y. Hayashi, and N. Hamada (2006), The 2004 Indian Ocean tsunami: Tsunamisource model from satellite altimetry, Earth Planets Space, 58, 195-201.

ImamuRa, F., N. Shuto, and C. Goto (1988), Numerical simulation of the transoceanic propagation of tsunamis, paper presented at the Sixth Congress of the Asian and Pacific Regional Division Int. Assoc. Hydraul. Res., Kyoto, Japan.

IshiI, M., P. M. Shearer, H. Houston, and J. E. Vidale (2005), Extent, duration and speed of the 2004 Sumatra-Andaman earthquake imaged by the Hi-Net array, Nature, 435, doi: 10.1038/nature03675.

KajIURA, K. (1963), The leading wave of a tsunami, Bull. Earth. Res. Inst., 41, 535-571.

KAme, N., J. R. Rice, and R. DMowsKa (2003), Effect of prestress state and rupture velocity on dynamic fault branching, J. Geophys. Res., 108(B5), 2265, doi:10.1029/2002JB002189.

KAто, T. (1983), High-angle reverse faulting associated with the 1946 Nankaido earthquake, Tectonophysics, 96, 31-44.

KING, G. C. P., R. S. Stein, and J. Lin (1994), Static stress changes and the triggering of earthquakes, Bull. Seis. Soc. Am., 84(3), 935-953.

KLINGelhoefer, F., et al. (2010), Limits of the seismogenic zone in the epicentral region of the 26 December 2004 great SumatraAndaman earthquake: Results from seismic refraction and wideangle reflection surveys and thermal modeling, J. Geophys. Res., 115, B01304, doi:10.1029/2009JB006569.

Kulikov, E. (2005), Dispersion of the Sumatra tsunami waves in the Indian Ocean detected by satellite altimetry, Tech. rep., P.P. Shirshov Institute of Oceanology, Russian Academy of Sciences, Moscow.

Kulikov, E. A., and P. P. Medvedev (2005), Satellite recording of the Indian Ocean tsunami on December 26, 2004, Doklady Earth Sciences, 401A(3), 444-448.

Lamb, S. H. (1932), Hydrodynamics, 6th ed., Cambridge University Press (reprinted 1945 by Dover Publications).

Lavigne, F., et al. (2009), Reconstruction of the tsunami inland propagation on December 26, 2004 in Banda Aceh, Indonesia, through field investigations, Pure and Applied Geophysics, 166, 259-281.

LAY, T., et al. (2005), The great Sumatra-Andaman earthquake of 26 December 2004, Science, 308, 1127-1133.

Lin, J.-Y., X. L. Pichon, C. Rangin, J.-C. Sibuet, and T. Maury (2009), Spatial aftershock distribution of the 26 December 2004 great Sumatran-Andaman earthquake in the northern Sumatra area, Geochem. Geophys. Geosys., 10(5), doi:10.1029/2009 GC002454.

Liu, Y., and J. R. Rice (2007), Spontaneous and triggered aseismic deformation transients in a subduction fault model, J. Geophys. Res., 112, B09404, doi:10.1029/2007JB004930. 
Loevenbruck, A., H. Hebert, F. Schindele, A. Sladen, F. Lavigne, D. Brunstein, P. Wassmer, and R. PARIs (2007), Detailed modeling of the 2004 tsunami flooding in the Banda Aceh and Lhok Nga districts (Sumatra, Indonesia), EOS Trans. AGU, 88(52), Fall Meet. Suppl., Abstract S53A-1042.

Lorito, S., A. Piatanesi, V. Cannelli, F. Romano, and D. Melini (2010), Kinematics and source zone properties of the 2004 Sumatra-Andaman earthquake and tsunami: Nonlinear joint inversion of tide gauge, satellite altimetry, and GPS data, J. Geophys. Res., 115, B02304, doi:10.1029/2008JB005974.

MeI, C. C. (1989), The Applied Dynamics of Ocean Surface Waves, World Scientific.

Meltzner, A. J., K. Sieh, M. Abrams, D. C. Agnew, K. W. Hudnut, J.-P. Avouac, and D. H. Natawidjaja (2006), Uplift and subsidence associated with the great Aceh-Andaman earthquake of 2004, J. Geophys. Res., 111, B02407, doi:10.1029/2005JB003 891.

Meltzner, A. J., K. Sieh, H.-W. Chiang, C.-C. Shen, B. W. Suwargadi, D. H. Natawidjaja, B. E. Philibosian, R. W. Briggs, and J. Galetzka (2010), Coral evidence for earthquake recurrence and an A.D. 1390-1455 cluster as the south end of the 2004 Aceh-Andaman rupture, J. Geophys. Res., 115, B10402, doi:10.1029/2010JB007499.

Milne-Thomson, L. M. (1968), Theoretical Hydrodynamics, 5th ed., Macmillan, London (reprinted 1996 by Dover Publications).

Mofjeld, H. O., V. V. Titov, F. I. Gonzalez, and J. C. Newman (2001), Tsunami scattering provinces in the Pacific Ocean, Geophysical Research Letters, 28(2), 335-338.

Mosher, D. C., J. A. A. JR, D. Fisher, and S. P. S. Gulick (2008), Deformation of the northern Sumatra accretionary prism for high-resolution seismic reflection profiles and ROV observations, Marine Geology, 252, 89-99.

NEIC (2004), http://earthquake.usgs.gov/earthquakes/eqinthenews/ 2004/us2004slav.

ОкаDA, Y. (1985), Surface deformation due to shear and tensile faults in a half-space, Bull. Seism. Soc. Am., 75, 1135-1154.

OKal, E. A., J. TALANDIER, and D. ReYmond (2007), Quantification of the hydrophone records of the 2004 Sumatra tsunami, Pure Appl. Geophys., 164, 309-323.

Park, J.-O., T. Tsuru, S. Kodaira, P. R. Cummins, and Y. Kaneda (2002), Splay fault branching along the Nankai subduction zone, Science, 297, 1157-1160.

Pesicek, J. D., C. H. Thurber, H. Zhang, H. R. DeShon, E. R. Engdahl, and S. WidiYANTORo (2010), Teleseismic doubledifference relocation of earthquakes along the Sumatra-Andaman subduction zone using a 3-D model, J. Geophys. Res., 115, B10303, doi:10.1029/2010JB007443.

Plafker, G., L. S. Cluff, X. Lloyd, S. P. Nishenko, Y. Stuart, and D. Syahrial (2006), The cataclysmic 2004 tsunami on $N W$ Sumatra - Preliminary evidence for a near-field secondary source along the Western Aceh Basin, Seis. Soc. Amer., Annual Meeting, San Francisco, CA.
Seeber, L., C. Mueller, T. Fujiwara, K. Arai, W. Soh, Y. S. DJajadihardja, and M.-H. Cormier (2007), Accretion, mass wasting, and partitioned strain over the 26 Dec 2004 Mw9.2 rupture offshore Aceh, northern Sumatra, Earth. Planet. Sci. Lett., 263, 16-31, doi:10.1016/j.eps1.2007.07.057.

Seno, T., and K. Hirata (2007), Did the 2004 Sumatra-Andaman earthquake involve a component of tsunami earthquakes? Bulletin of the Seismological Society of America, 97(1A), S296S306, doi:10.1785/01020050615.

Shuto, N., K. Chida, and F. Imamura (1995), Generation mechanism of the first wave of the 1983 Nihonkai-Chubu earthquake tsunamis, in Tsunami: -Progress in Prediction, Disaster Prevention and Warning, edited by Y. Tsuchiya and N. Shuto, pp. 37-53, Kluwer Academic Publishers, Dordrecht.

Sibuet, J.-C., et al. (2007), 26th December 2004 great SumatraAndaman earthquake: Co-seismic and post-seismic motions in northern Sumatra, Earth and Planet. Sci. Lett., 263, 88-103, doi:10.1016/j.eps1.2007.09.005.

SLAdEN, A., and H. Hebert (2008), On the use of satellite altimetry to infer the earthquake rupture characteristics: Application to the 2004 Sumatra event, Geophys. J. Int., 172(2), 707-714.

Smith, W. H., R. Scharroo, V. V. Titov, D. Arcas, and B. K. ARBIC (2005), Satellite altimeters measure tsunami, Oceanography, 18(2), 10-12.

Smith, W. H. F., and D. T. SANDwell (1997), Global seafloor topography from satellite altimetry and ship depth soundings, Science, 277, 1957-1962.

Suppe, J. (1983), Geometry and kinematics of fault-bend folding, Amer. J. Sci., 283, 684-721.

SynOLAKIS, C. E. (1991), Green's las and the evolution of solitary waves, Phys. Fluids, 3(3), 490-491.

TANioKa, Y., and K. SATAKE (2001), Coseismic slip distribution of the 1946 Nankai earthquake and aseismic slips caused by the earthquake, Earth Planets Space, 53, 235-241.

Tilmann, F. J., T. J. Craig, I. Grevemeyer, B. Suwargadi, H. Kopp, and E. FLuEH (2010), The updip seismic/aseismic transition of the Sumatra megathrust illuminated by aftershocks of the 2004 AcehAndaman and 2005 Nias events, Geophys. J. Int., 181, 1261-1274, doi:10.1111/j.1365-246X.2010.04597.x.

Titov, V., A. B. Rabinovich, H. O. Mofjeld, R. E. Thomson, and F. I. GonZalez (2005), The global reach of the 26 December 2004 Sumatra tsunami, Science, 309, 2045-2048.

Tsai, V. C., M. Nettles, G. Ekstrom, and A. M. Dziewonski (2005), Multiple CMT source analysis of the 2004 Sumatra earthquake, Geophys. Res. Lett., 32, L17304, doi:10.1029/2005 GL023813.

WANG, X., and P. LiU (2006), An analysis of the 2004 Sumatra earthquake fault plane mechanisms and Indian Ocean tsunami, Journal of Hydraulic Research, 44(2), 147-154.

Wendt, J., D. D. Oglesby, and E. L. Geist (2009), Tsunamis and splay fault dynamics, Geophys. Res. Lett., 36, L15303, doi: 10.1029/2009GL038295. 